\title{
Online Appendix: Unemployment Insurance and Means-Tested Program Interactions: Evidence from Administrative Data
}

\author{
Pauline Leung Christopher O'Leary
}

\section{A Means-Tested Programs Primer}

\section{A.1 Temporary Assistance For Needy Families (TANF)}

TANF provides cash assistance to families with dependent children. The size of the benefit is dependent on family size and income. In Michigan, the maximum benefit guarantee is approximately equal to 35 percent of the federal poverty level and the benefit reduction rate is 80 percent for earned income over $\$ 200$ and 100 percent for unearned income (e.g., UI). In addition to the income test, TANF participants are also subject to other requirements, including an asset test, work requirements, and time limits. In Michigan specifically, adult enrollees must have less than $\$ 3,000$ in assets, work or participate in training, and are limited to a lifetime total of 48 months of aid. ${ }^{1}$ Perhaps because of the latter two requirements, which increase costs and diminish the value of being on the program, the take-up rate of TANF is low, estimated to be around 36 percent of eligibles nationally in 2007 (Loprest, 2012).

\section{A.2 Supplemental Nutrition Assistance Program (SNAP)}

SNAP, formerly the Food Stamp Program, provides individuals and families with a benefit voucher that can be spent on food. The income limit for SNAP is 200 percent of the federal poverty line. However, states have some scope to allow families who are already receiving services from specific means-tested programs to be categorically eligible for SNAP.

Benefit levels are set nationally and depend on family size and income. The maximum benefit guarantee is determined by the cost of the a Thrifty Food Plan, which is calculated

\footnotetext{
${ }^{1}$ The 48-month time limit was signed into law in 2006.
} 
by the U.S. Department of Agriculture to represent the lowest cost nutritious diet. It is approximately equal to 30 percent of the federal poverty line. Benefits are subject to a 30 percent benefit reduction rate. The income that is subject to the benefit reduction rate is referred to as "net income" and is calculated by taking all income, and subtracting a standard deduction, 20 percent of earnings, child support and dependent care spending, and some shelter costs.

Apart from income requirements, SNAP recipients are also required to work or engage in job search-related activities, though certain groups (e.g., the elderly or disabled) are exempt. ${ }^{2}$ Take-up of SNAP benefits is much higher than for TANF: Nationally, the take-up rate is estimated to be at approximately 65 percent in 2005, and up to 80 percent in 2010 (Ganong and Liebman, 2013).

\section{A.3 Medicaid}

During the study period in Michigan, there were 40 different channels through which individuals could have potentially qualified for some type of Medicaid coverage (Center for Healthcare Research and Transformation 2012). We focus here on programs available to healthy adults, since we are interested in program participation among UI claimants. The Low Income Families (LIF) program is available to families with dependent children who meet income requirements, at around 35 percent of the federal poverty level. It comes automatically with TANF enrollment, though TANF enrollment is not necessary. If the family is no longer eligible for LIF due to income changes, a program called "Transitional Medical Assistance" grants continuing coverage for 12 months. The Adult Medical Program, which is for low income adults without children, provides less comprehensive benefits.

Several narrowly defined categories of adults have higher income limits: Pregnant women under 185 percent of the poverty line are covered during and a few months after pregnancy, and those under age 19 at less than 150 percent of poverty are also eligible. Finally, parents and those under age 21 could potentially also qualify for Medicaid even if they exceed income limits but have high medical expenses ("medically needy").

\footnotetext{
${ }^{2}$ Because of categorical eligibility, there was effectively no asset test during the study period in Michigan.
} 
The value of Medicaid can be approximated by per-enrollee spending, which was $\$ 3,073$ for adults in Michigan during 2011 (Kaiser Family Foundation 2015). Unlike TANF or SNAP, eligibility for UI does not diminish the size of the benefit, unless income exceeds the eligibility limit. Sommers and Epstein (2010) estimates the take-up rate of adult Medicaid to be about 76 percent in Michigan, compared to a national average of 62 percent. $^{3}$

\section{B Data Appendix}

\section{B.1 Sample Construction}

Our data covers the universe of regular initial UI claims made in Michigan from 2005 through 2010. ${ }^{4}$ Regular initial claims are applications for benefits from the state's regular (nonextension) UI programs and are typically filed around the time of layoff. Since the benefit formula is based on recent prior earnings, it is advantageous for the worker to claim as soon as possible after job loss to receive the highest benefit. After a worker files the initial claim, she may draw weekly benefits until she uses up her benefit allocation (up to 26 weeks of benefits) during a one-year period ("benefit year").

Starting with the universe of regular claims, we restrict the analysis sample to claims that were made more than two years after a prior claim if a worker was observed have made multiples claims over the study period. The primary reason for not including claims made shortly after a prior claim is that these claimants were unlikely to be newly unemployed. Because an initial claim is only valid for one year, workers who are still unemployed or on a subsequent spell of unemployment at the end of the benefit year must file another initial claim and establish a new benefit year in order to continue receiving benefits. During the Great Recession, workers must establish a new benefit year to receive EB or EUC benefits from the previous year's claim. For these reasons, we observe a mass of claims filed on or shortly after the one-year anniversary of a previous claim in the data. Although many of these claims made near the end of a benefit year appear to be monetarily ineligible based on recent prior earnings, the worker may simply be continuing a benefit spell from a past claim.

\footnotetext{
${ }^{3}$ This take-up rate includes adults with disabilities.

${ }^{4}$ We actually observe regular claims made as early as 2001 , but program participation data are not available before 2005 .
} 
A secondary reason for eliminating claims made within two years of a prior claim is that, starting in mid 2010, newly eligible claimants who had a previous higher, unexhausted EUC claim were allowed to receive the same weekly benefit as the unexhausted claim. ${ }^{5}$ Therefore, after this new policy was in place, it is possible that eligible claimants received a much higher benefit relative to eligible claimants from before the policy change. Since we cannot observe which claimants have unexhausted benefits, we exclude all claims that occur within two years after another claim, under the assumption that after two years, claimants are unlikely have previously unexhausted benefits.

For all samples, we exclude any claimants with wage outliers - that is, those who earn more than half million dollars in any single quarter.

\section{Minimum Earnings Threshold Sample (Main RD Analysis Sample)}

The main analysis sample used starts with the set of "new claims" that were made at least two years after a prior claim describe above. We further restrict the sample to those whose highest quarterly earnings of the previous five quarters are within $\$ 1,500$ of the relevant minimum high quarter wage for UI eligibility. Since the lowest eligibility threshold over the sample period is $\$ 1,998$, we do not include any claims that have zero earnings. Finally, we include only claims for which the base period earnings (under standard or alternative base periods) are above 1.5 times the high quarter earnings. This analysis sample contains 252,616 claims.

\section{Earnings Distribution Sample (Alternative RD Sample)}

The sample used in Section 4.B used to explore the impact of being just eligible due to the earnings distribution requirement begins with "new claims" as described above. We then restrict the sample to only those whose base period earnings are larger than the high quarter earnings but less than twice as large. If the ratio between base period earnings and high quarter earnings differ using the standard base period or the alternative base period, we use base period that yields the higher ratio. Finally, we exclude claims that do not meet the

\footnotetext{
${ }^{5}$ The Unemployment Compensation Extension Act of 2010 states that if the new weekly benefit is at least either $\$ 100$ or 25 percent less than the benefit from the old claim, states may continue payment of the old EUC benefits and defer the new claim, or supplement the regular benefit with the difference.
} 
minimum high quarter earnings requirement. This analysis sample contains 126,616 claims.

\section{Maximum Benefit Sample (RKD Sample)}

The sample used in Section 4.B to explore the impact of the weekly benefit cap begins with "new claims" as described above. We then calculate the base period and high quarter earnings using standard and alternative base periods and keep only claims that were monetarily eligible and were not disqualified due to a fire or voluntary quit. The weekly benefit level is equal to 4.1 percent of the high quarter earnings plus $\$ 6$ per dependent (up to 5 dependents), capped at $\$ 362$ during the sample period. Since the high quarter earnings are used to determine the benefit level, it matters whether or not a worker qualified for benefits via the standard or alternative base period. We use the standard base period if a worker meets both minimum and distribution requirements for monetary eligibility under the standard base period, and the alternative base period otherwise. We normalize each claimant's high quarter earnings to the high quarter earnings required to maximize the benefit level (i.e., the kink location), which varies by the number of dependents. Finally, we restrict the sample to claimants who are within $\$ 5,000$ of kink threshold. Note that the kink threshold ranges from about $\$ 8,097$ (for five dependents) to $\$ 8,829$ (for no dependents), so that the claimants with the lowest high quarter earnings in the sample are still high enough to be monetarily eligible for benefits (i.e., this sample does not overlap with the main RD sample). ${ }^{6}$ This analysis sample contains 925,013 claims.

\section{B.2 Censored Means-Tested Outcomes}

Since we have means-tested program data from 2005 through the August of 2011, we do not observe two full years of followup for claims that are made starting in the third quarter of 2009. This does not affect the findings in Figure 4 and Panel A of Table 3, as we observe means-tested program participation in the quarter following the claim for everyone in our sample. However, the censored program data does affect our crowdout estimates (Panel B of Tables 3 and 4) and the dynamic effects in Figure 5 and Table A.3.

For the estimates of benefit crowdout over the two years post-claim (Panel B of Tables

\footnotetext{
${ }^{6}$ The minimum high quarter wage for UI eligibility ranges from $\$ 1,998$ to $\$ 2,871$ over the sample period.
} 
3 and 4), we artificially censor the first stage (UI entitlement) when we do not observe the entire followup period for the outcome. For example, we only observe means-tested program use for a claimant who filed in the beginning of 2010 for the next one and a half years. Therefore, for this observation, we artificially set the UI benefit entitlement to the amount of UI the worker is entitled to over the next one and a half years even if she is entitled to more benefits. This way, we can interpret the crowdout estimates as the dollar reduction in meanstested program benefits per dollar of UI benefit entitlement. The uncensored first stage is shown in Panel B of the Appendix Table A.1 when we consider labor market outcomes (where have a longer followup). The uncensored first stage is approximately 12 percent larger.

The dynamic effects of UI eligibility shown in Figure 5 are also complicated by the fact that we do not observe means-tested program use for the full followup period for some claimants. Specifically, estimates for quarters 0 to 3 use the entire sample, estimates for quarter 4 are missing claims filed in the last quarter of 2010, estimates for quarter 5 are missing claims filed in the last two quarters of 2010, etc. Therefore, if the dynamic effects change for different cohorts of UI claimants, the patterns of Figure 5 would reflect a combination of dynamic effects and a changing composition of workers. However, we believe that the dynamic effects are relatively stable for cohorts that filed claims over the 2009-2010. First, the level of means-tested benefits at the threshold remains stable throughout the followup period, even as the cohorts change (see first two columns of Table A.3). This means that the level of means-tested program use in the 2009-2010 cohorts were unlikely to be trending up or down, which would have resulted in a trend in estimated intercept below the threshold over time. Second, even though the cohorts are changing smoothly over the 4th through 10th quarter of Figure 5 (i.e. there are not sharp increases in claims in any one quarter of 20092010), there are no sharp changes in the pattern until quarter the 10th quarter (for TANF), which follows benefit exhaustion for many workers in the sample. 


\section{B.3 Variable Definitions \\ Potential Duration}

Since the data contain only regular UI claims, we do not observe the potential duration of benefits when extension programs are in effect. For our sample period, benefits were extended by up to 20 weeks by the federal-state Extended Benefit (EB) program and up to 53 weeks by the federal Emergency Unemployment Compensation (EUC) program. We use the timing of when each extension was in effect to estimate how many weeks of UI each claimant was entitled to receive. In general, if a claimant has exhausted all available regular benefits and an extended benefit program was in effect, she would be eligible to receive extended benefits. Workers must exhaust regular benefits before receiving benefits from (each of four tiers of) EUC, and all EUC benefits must be exhausted before receiving EB.

We calculate the potential duration by assuming that workers claim benefits every week starting at the beginning of their benefit year. We use the following extension program dates to determine the number of weeks of extended benefits a claimant potentially receives:

- EUC Tier 1

- If a worker exhausts regular benefits between June 30, 2008 and November 21, 2008, she is eligible for an extra 0.5 times her regular benefit entitlement. For example, if a worker is eligible for 26 weeks of regular benefits, she is eligible for 13 extra weeks under Tier 1 of EUC. On the other hand, a worker who is eligible for 20 weeks of regular benefits will be eligible for 10 extra weeks under Tier 1 of EUC.

- If a worker exhausts regular benefits after November 21, 2008, she is eligible for an extra 0.8 times her regular benefit entitlement (up to 20 weeks).

- EUC Tier 2

- If a worker exhausts regular and EUC Tier 1 benefits between November 21, 2008 and November 6, 2009, she is eligible for an extra 0.5 times her regular benefit entitlement (up to 13 weeks).

- If a worker exhausts regular and EUC Tier 1 benefits after November 6, 2009, 
she is eligible for an extra 0.54 times her regular benefit entitlement (up to 14 weeks).

- EUC Tier 3

- If a worker exhausts regular, EUC Tier, 1 and EUC Tier 2 benefits after November

6, 2009, she is eligible for an extra 0.5 times her regular benefit entitlement (up to 13 weeks).

- EUC Tier 4

- If a worker exhausts regular, EUC Tiers 1, 2, and 3 benefits after November 6, 2009, she is eligible for an extra 0.24 times her regular benefit entitlement (up to 6 weeks).

- $\underline{E B}$

- If a worker exhausts regular and all EUC tiers benefits between January 4, 2009 and January 12, 2012, she is eligible for an extra 0.8 times her regular benefit entitlement, or until February 18, 2012, whichever comes first (up to 20 weeks). Unlike EUC, once an EB period has expired, payments also stop.

The actual potential duration of workers may differ from this calculated potential duration if claimants worked or did not claim benefits every week as assumed. It is also worth noting that although calculated potential duration can be as high as 99 weeks, the expected potential duration at any point during the unemployment spell was typically much shorter as EUC was only legislated to be in effect for short periods of time. For more detail on the timing of the EUC program, see Rothstein (2011).

\section{Reemployment Wage Change}

Since we observe earnings at a quarterly frequency and do not have any measure of hours or weeks worked per quarter, it is difficult to distinguish between low wage rates and few hours worked for any given quarter. This is especially problematic when we are trying to estimate the impact of UI eligibility on reemployment wages as workers who are reemployed in the middle of a quarter will only have worked for an unknown proportion of the quarter. We are similarly be unable to observe past wages. 
Therefore, we define past quarterly earnings as the maximum quarterly earnings of the base period (i.e., five quarters prior to UI claim), as it is most likely to represents a "full" quarter of employment. This measure of past quarterly earnings also has the advantage of being defined for all claimants in the sample, since we have already restricted the sample to those with positive high quarter earnings. Similarly, and symmetrically, we define the reemployment quarterly earnings as the maximum quarterly earnings within five quarters after a worker first reports positive earnings (i.e., exits nonemployment). The reemployment earnings change is define as the difference between log reemployment earnings and log past earnings.

\section{Quarterly UI Income}

A measure of quarterly UI income is needed in Section 3.B to assess the relative contributions of the UI program and other means-tested programs to overall income during unemployment. Since we only observe regular UI claims, which does not contain information of extended benefits or the timing of benefit payments, we use the following procedure to estimate the the amount of UI income each claimant receives in per quarter:

1. We start by calculating the potential benefit duration, including extended benefits. This is done by assuming the worker claims continuously and that they are eligible for extension programs that are in place at the time the worker exhausts each tier of benefits, as described above.

2. Starting with the benefit begin date, we will assume a worker receives as many UI weeks as there are in the quarter, up to the number of UI weeks they have remaining.

(a) According to UI rules, if a worker has earnings in any week, they may or may not be able to receive benefits. The partial unemployment payment rule in Michigan allows for UI benefits to be paid if the worker earns less than 1.5 times the weekly benefit amount, though UI payments will be lowered for that week. ${ }^{7}$ We do not know which weeks of a given quarter a worker is employed, which prevents us from implementing the partial benefit rules as stated. Therefore, we will use the

\footnotetext{
${ }^{7}$ The partial unemployment rule is that the benefits will be reduced by 50 cents per dollar of earnings.
} 
following rule to approximate the amount of UI claimed per quarter:

i. If the weekly average earnings in the quarter are less than the weekly benefit amount, we assume the worker receives the weekly benefit amount for all weeks.

ii. If the weekly average earnings are between 1 and 1.5 times the weekly benefit amount, the amount of UI is reduced by 50 percent of earnings. We assume that the workers use up $\frac{\text { Total UI Received in Qtr }}{\text { Weekly Benefit Amount }}$ weeks of benefits.

iii. If the weekly average earnings are more 1.5 times the weekly benefit amount, we assume the worker receives zero UI and does not use up any UI weeks that quarter.

(b) Workers continue receiving benefits until they run out of UI weeks.

(c) For workers who start the benefit year after 2008, benefits can be "rolled" over to the next benefit year, for up to two years post claim. In general, a single UI claim can only be paid out over a one year period (i.e., no rolling over). However, during the Great Recession period, when a series of extended benefit programs were available, workers were able to continue onto extended benefit tiers even after the benefit year ends.

3. Since it is also possible that some workers with no earnings in later quarters have exited the labor force (to pursue further education, to retire, or to collect disability insurance, for example), we further adjust UI receipt downward by a factor of 0.764 if a worker has no earnings in the 2nd or later quarters after the UI claim. This is based on the finding in Krueger, Cramer and Cho (2014) that 33.7 percent of workers who are unemployed for over 27 weeks exit the labor force 15 months later.

\section{Tax Rates}

Since we do not observe family structure and household income, we apply the same tax schedule to all workers in our sample for the calculations in Section 3.B. Payroll taxes are assumed to be 7.65 percent. To estimate income taxes, we calculate the amount of taxes owed in 2008 for five quarterly earnings bins using NBER Internet TAXSIM version 9: \$0 
to $\$ 2000, \$ 2001$ to $\$ 4000, \$ 4001$ to $\$ 6000, \$ 6001$ to $\$ 8000, \$ 8001+$. For each earnings bin, we keep household characteristics, other income, and expenditures constant. Specifically, we assume that workers are married, have one dependent child, and live in Michigan. For spousal earnings, dividends, pensions, social security benefits, transfers, rental payment, property tax payments, and mortgages, we use the averages for individuals in the ACS who live in Michigan, are 20-54 years old and have annual earnings less than that of a worker who earns the minimum wage and employed 30 hours a week. The resulting tax rates (including payroll, state income, and federal income taxes) ranged from 11.1 percent for the lowest earnings bin to 19.3 percent (for the highest earnings bin). When we report post-tax UI income, we subject UI to income taxes but not the payroll tax.

\section{B.4 Earnings Requirements Across States}

In Appendix Figure A.1, we show how monetary eligibility requirements differ across states. Since several states' eligibility requirements (like Michigan's) involve both a minimum earnings level and sufficient earnings spread throughout the base period, we construct an eligibility measure that incorporates both requirements. The information on earnings requirements is from the 2010 Comparison of State Unemployment Laws, supplemented with verification using state UI websites.

The eligibility index in Appendix Figure A.1 is constructed as follows. Using the 2010 American Community Survey, we restrict the sample to workers age 18 to 65, who are not in school, who are not self-employed or unpaid family workers, who worked in the past year, and who are in the labor force. We then predict the probability of unemployment using demographic (sex, age categories, marital status, race, ethnicity, and educational attainment) and industry information, keeping only employed workers who have an above-median probability of becoming unemployed. This step is to identify a group of workers who are currently employed but are "at risk" for unemployment. Relative to all employed workers, this "likely unemployed" group of workers are more observably similar to unemployed workers. For example, among the "likely unemployed" workers, 66 percent have a high school diploma or less, 15 percent are African American, 42 percent are age 35 or under, and 35 percent are 
married with a spouse present. Of the unemployed, 62 percent have a high school diploma or less, 14 percent are African American, 42 percent are age 35 or under, and 41 percent are married with a spouse present. In contrast, among all employed workers, 42 percent have a high school diploma or less, 9 percent are African American, 30 percent are age 35 or under, and 60 percent are married with a spouse present. ${ }^{8}$

Finally we take a random sample of 30,000 "likely unemployed", but currently employed, workers. The eligibility index for each state is the proportion of this sample who would be monetarily eligible for benefits if they were laid off at the time of their survey response, assuming that they lived in each state. This measure is essentially a summary of the eligibility rules and varies only by state policy, similar to the simulated instrument used by Cutler and Gruber (1996). Since we only observe earnings in the past 12 months and quarters worked (i.e., binned weeks worked), we assume that the earnings are evenly distributed in the quarters worked. This means that when there are earnings distribution requirements, we are likely to overstate the percent eligible, as we artificially smooth earnings over the base period. ${ }^{9}$ In states that have minimum weekly wage requirements, we assume that the number of weeks worked is the midpoint of the weeks worked interval. In Washington, where there are minimum hours requirements, we assume that workers are employed for their usual weekly hours multiplied by the midpoint of their weeks worked interval.

\section{B.5 Characteristics of Monetarily Ineligible Workers Across States}

In Appendix Figure A.10, we show how characteristics of monetarily ineligible workers vary with the stringency of monetary eligibility requirements. Specifically, we construct summary measures of demographic and industry characteristics for employed workers who are "at risk" for unemployment and would be monetarily ineligible for UI in their respective states. ${ }^{10}$ We then plot these summary measures of worker characteristics against the

\footnotetext{
${ }^{8}$ We cannot calculate the UI eligibility rates of unemployed workers because we do not know how long they have been unemployed and their earnings at the point of layoff.

${ }^{9}$ We can, however, deem a worker ineligible if they only have one quarter of earnings and the state has an earnings distribution requirement.

${ }^{10}$ As above, we look at would-be monetarily ineligible employed (rather than unemployed) workers because we can more accurately gauge their recent work history in the ACS.
} 
simulated monetary eligibility measure described in Appendix Section B.4.

The summary measures of worker characteristics are constructed as follows. Using the 2005-2010 American Community Survey, we restrict to workers age 18 to 65, who are not in school, who are not self-employed or unpaid family workers, who worked in the past year, and who are in the labor force. Within the sample of unemployed workers, we linearly regress participation in each means-tested program on demographic characteristics (gender, age category, marital status, race, ethnicity, number of children, number of children under 5 , and education). We use the parameter estimates of this regression to calculate the predicted probability of participation in each means-tested program during unemployment for workers who were currently employed. The predicted program participation is simply a linear combination of fixed worker characteristics with weights that correspond with importance in determining program participation. We then eliminate workers who are not likely to be unemployed (i.e., less than the median probability of unemployment using the procedure described in Appendix Section B.4 to predict unemployment) or who would be monetarily eligible for UI if they become unemployed. We are left with a sample of currently unemployed workers who are "at risk" of entering unemployment without UI. In Appendix Figure A.10 we are plotting the mean predicted probability of participating in each means-tested program for each state against the simulated eligibility measure described in Appendix Section B.4. The plots show that the predicted probability of participating in each means-tested program does not vary much with eligibility stringency, indicating that the workers who are ineligible for UI in each state are similar despite the differences in eligibility requirements. ${ }^{11}$

For reference, we also overlay the actual program participation rates for the same sample in Appendix Figure A.10. The comparisons between the actual and predicted program participation rates suggest that worker characteristics explain much of the participation rates of TANF and SNAP, but less so for Medicaid. This is perhaps due to the fact that Medicaid policies are vastly different across states (Appendix Figure A.3).

\footnotetext{
${ }^{11}$ Although these eligibility measures are for 2010 , there is fairly minimal change in the ranking of monetary eligibility stringency measures across states in the 2005-2010 period.
} 


\section{Optimal UI Eligibility Framework}

In this section, we present a simple model that can be used to assess the welfare benefits of decreasing the UI eligibility threshold. It is similar in spirit to the models of optimal unemployment insurance, e.g., Baily (1978) and Chetty (2008), wherein the social planner balances the consumption smoothing benefits of providing UI with the cost of reduced job search effort. Unlike classic models of optimal UI in which the social planner considers marginal changes in the benefit level, the social planner considers the impact of making a marginal worker eligible for benefits.

\section{Workers' Problems}

Workers allocate their one unit of time between (re)employment and unemployment, and incur a cost of working that is given by a strictly convex cost function $\psi(\cdot)$. An unemployed worker who is eligible for UI allocates $s_{U I} \in(0,1)$ to employment and spends $1-s_{U I}$ of time unemployed. Therefore, the UI-eligible worker's utility is given by

$$
V_{U I}=\max _{s_{U I}}\left(1-s_{U I}\right) u\left(c_{U I}^{u}\right)+s_{U I} u\left(c^{e}\right)-\psi\left(s_{U I}\right)
$$

Similarly, the worker who is ineligible for UI spends $s_{-U I}$ and $1-s_{-U I}$ of the period employed and unemployed, respectively. This worker's utility is

$$
V_{-U I}=\max _{s_{-U I}}\left(1-s_{-U I}\right) u\left(c_{-U I}^{u}\right)+s_{-U I} u\left(c^{e}\right)-\psi\left(s_{-U I}\right)
$$

We assume for now that during unemployment, consumption will equal to all income, including UI benefits $b$, benefits from other social programs $g_{U I}$ or $g_{-U I}$, and outside income $q: c_{U I}^{u}=b+g_{U I}+q$ and $c_{-U I}^{u}=g_{-U I}+q$. During employment, both UI-eligible and ineligible workers earn the same wage $w$ and pay a lump-sum tax $\tau$, so that $c^{e}=w-\tau$. Note that eligibility for UI does not affect the outside income $q$ or future wages $w$. If eligibility is determined by a cutoff rule along previous earnings, this assumption might be reasonable within a neighborhood of the UI threshold, since workers earn approximately the same pre- 
layoff. The empirical part of the paper shows that UI eligibility reduces income received from other social programs $\left(g_{-U I}>g_{U I}\right)$, but that income is still higher for UI eligible work$\operatorname{ers}\left(c_{U I}^{u}>c_{-U I}^{u}\right)$

A UI-eligible worker determines her duration of employment $s_{U I}$ by the solving following equation:

$$
-u\left(c_{U I}^{u}\right)+u\left(c^{e}\right)=\psi^{\prime}\left(s_{U I}\right)
$$

Similarly, a UI-ineligible worker will solve

$$
-u\left(c_{-U I}^{u}\right)+u\left(c^{e}\right)=\psi^{\prime}\left(s_{-U I}\right)
$$

Note that since UI-ineligible workers consume less while unemployed, $c_{-U I}^{u}<c_{U I}^{u}$, their optimal duration of employment will be higher than eligible workers $\left(s_{-U I}>s_{U I}\right)$.

\section{Social Planner's Problem}

Let $H\left(w_{p}\right)$ be the cumulative distribution of pre-layoff earnings $w_{p}$. As in reality, workers are more likely to be eligible for UI if their pre-layoff earnings are above an eligibility threshold $G$. Let the probability of eligibility be $P_{A}$ and $P_{B}$ if $w_{p} \geq G$ and $w_{p}<G$, respectively, and $P_{A}>P_{B}$. Therefore, the proportion of society ineligible for UI is $F(G) \equiv H(G)\left[1-P_{A}\right]+[1-$ $H(G)]\left[1-P_{B}\right]$. The utilitarian planner's objective is to maximize societal utility by choosing the eligibility threshold $G$ such that benefits from all social programs equal the tax collected:

$$
\begin{aligned}
\max _{G} W(G)= & F(G) V_{-U I}+[1-F(G)] V_{U I} \\
\text { s.t. } & F(G)\left(1-s_{-U I}\right) g_{-U I}+[1-F(G)]\left(1-s_{U I}\right)\left(b+g_{U I}\right) \\
& =\tau\left(F(G) s_{-U I}+[1-F(G)] s_{U I}\right)
\end{aligned}
$$

We will assume that workers do not respond to the eligibility threshold $G$ by changing their pre-layoff employment behavior (i.e., sorting around the threshold), which is supported by our data. Letting $f(x) \equiv\left[P_{B}-P_{A}\right] h(x)$, the marginal welfare increase of lowering the eligi- 
bility threshold is thus given by

$$
\begin{aligned}
-\frac{d W}{d G}= & -f(G) V_{-U I}-F(G) \frac{\partial V_{-U I}}{\partial \tau} \frac{\partial \tau}{\partial G}+f(G) V_{U I}-[1-F(G)] \frac{\partial V_{U I}}{\partial \tau} \frac{\partial \tau}{\partial G} \\
= & f(G)\left[V_{U I}-V_{-U I}\right]+\left\{F(G) s_{-U I}+[1-F(G)] s_{U I}\right\} u^{\prime}\left(c^{e}\right) \frac{\partial \tau}{\partial G} \\
\approx & f(G)\left(1-s_{-U I}\right)\left[u\left(c_{U I}^{u}\right)-u\left(c_{-U I}^{u}\right)\right] \\
& +\left\{F(G) s_{-U I}+[1-F(G)] s_{U I}\right\} u^{\prime}\left(c^{e}\right) \frac{\partial \tau}{\partial G}
\end{aligned}
$$

where the second line follows from $\frac{\partial V_{-U I}}{\partial \tau}=-s_{-U I} u^{\prime}\left(c^{e}\right)$ and $\frac{\partial V_{U I}}{\partial \tau}=-s_{U I} u^{\prime}\left(c^{e}\right)$. The third line follows from the workers' optimality conditions (1) and (2) and a first order Taylor expansion of $\psi\left(s_{-U I}\right)$ around $s_{U I} \cdot{ }^{12}$ The first term of Equation (9) reflects the benefits of making marginal worker at the UI threshold eligible for UI, while the second term reflects tax costs. Note that the workers' optimality conditions ensure that, to a first order, the gain from making a worker eligible for UI is the change in utility during unemployment, scaled by the length of time unemployed.

Note that the government budget constraint can be written as

$$
\tau=\frac{F(G)\left(1-s_{-U I}\right) g_{-U I}+[1-F(G)]\left(1-s_{U I}\right)\left(b+g_{U I}\right)}{F(G) s_{-U I}+[1-F(G)] s_{U I}}
$$

which yields

$$
\begin{aligned}
\frac{\partial \tau}{\partial G}= & f(G) \frac{\left(1-s_{-U I}\right) g_{-U I}-\left(1-s_{U I}\right)\left(b+g_{U I}\right)}{F(G) s_{-U I}+[1-F(G)] s_{U I}} \\
& -\frac{f(G)\left(s_{-U I}-s_{U I}\right) \tau}{F(G) s_{-U I}+[1-F(G)] s_{U I}}
\end{aligned}
$$

Plugging this expression back into (3) we have:

$$
\begin{aligned}
-\frac{d W}{d G} \approx & f(G)\left(1-s_{-U I}\right)\left[u\left(c_{U I}^{u}\right)-u\left(c_{-U I}^{u}\right)\right] \\
& -u^{\prime}\left(c^{e}\right) f(G)\left[\left(1-s_{U I}\right)\left(b+g_{U I}\right)-\left(1-s_{-U I}\right) g_{-U I}+\left(s_{-U I}-s_{U I}\right) \tau\right]
\end{aligned}
$$

\footnotetext{
${ }^{12}$ The approximation provides a lower bound for the welfare gain. That is, the true welfare gain is more positive than the expression in equation (9).
} 
Further scaling the welfare gain by the welfare equivalent of an increased dollar of consumption for the marginal worker, $f(G) u^{\prime}\left(c^{e}\right)$,

$$
\begin{aligned}
-\frac{d \tilde{W}}{d G} \equiv-\frac{\frac{d W}{d G}}{f(G) u^{\prime}\left(c^{e}\right)} \approx & \left(1-s_{-U I}\right) \frac{u\left(c_{U I}^{u}\right)-u\left(c_{-U I}^{u}\right)}{u^{\prime}\left(c^{e}\right)} \\
& -\left[\left(1-s_{U I}\right)\left(b+g_{U I}\right)-\left(1-s_{-U I}\right) g_{-U I}+\left(s_{-U I}-s_{U I}\right) \tau\right](5)
\end{aligned}
$$

The second line shows that impact of lowering the eligibility threshold on the government budget is equivalent to the net difference in benefit outlays between a UI-eligible and ineligible worker (mechanical effect), and a loss of tax revenues resulting from the difference in employment durations. As noted by Lawson (2017), difference in employment durations becomes more consequential as (UI and non-UI) government spending increases.

A "sufficient statistics" expression of $-\frac{d \tilde{W}}{d G}$ that does not contain utility terms can be obtained by taking two first order Taylor expansions (of $u\left(c_{U I}^{u}\right)$ around $c_{-U I}^{u}$ and then $u^{\prime}\left(c_{-U I}^{u}\right)$ around $\left.c^{e}\right)$,

$$
\begin{aligned}
-\frac{d \tilde{W}}{d G} \approx & \left(1-s_{-U I}\right)\left(c_{U I}^{u}-c_{-U I}^{u}\right) \frac{u^{\prime}\left(c_{-U I}^{u}\right)}{u^{\prime}\left(c^{e}\right)} \\
& -\left[\left(1-s_{U I}\right)\left(b+g_{U I}\right)-\left(1-s_{-U I}\right) g_{-U I}+\left(s_{-U I}-s_{U I}\right) \tau\right] \\
\approx & \left(1-s_{-U I}\right)\left(c_{U I}^{u}-c_{-U I}^{u}\right)\left(1+R \frac{\Delta c}{c^{e}}\right) \\
& -\left[\left(1-s_{U I}\right)\left(b+g_{U I}\right)-\left(1-s_{-U I}\right) g_{-U I}+\left(s_{-U I}-s_{U I}\right) \tau\right]
\end{aligned}
$$

where $R=-\frac{c^{e} u^{\prime \prime}\left(c^{e}\right)}{u^{\prime}\left(c^{e}\right)}$, the coefficient of relative risk aversion, and $\Delta c=c^{e}-c_{-U I}^{u}$. To estimate the welfare gains of lowering the UI eligibility threshold, we can plug in estimates of the duration of unemployment for eligible and ineligible workers $\left(1-s_{U I}\right.$ and $\left.1-s_{-U I}\right)$, UI and non-UI benefit levels $\left(b, g_{U I}\right.$, and $\left.g_{-U I}\right)$, and consumption levels (which equals to income) while employed and unemployed $\left(c^{e}, c_{U I}^{u}, c_{-U I}^{u}\right)$ into (5) or (6). If we use equation (5), we will also need to specify a utility function while equation (6) only requires a value of relative risk aversion.

Although we have so far assumed that workers consume all their incomes, a modification 
of equation (6) loosens this assumption. Specifically, we can write (6) as

$$
\begin{aligned}
-\frac{d \tilde{W}}{d G} \approx & \left(1-s_{-U I}\right) \rho\left(y_{U I}-y_{-U I}\right)\left(1+R \frac{\Delta c}{c^{e}}\right) \\
& -\left[\left(1-s_{U I}\right)\left(b+g_{U I}\right)-\left(1-s_{-U I}\right) g_{-U I}+\left(s_{-U I}-s_{U I}\right) \tau\right]
\end{aligned}
$$

where $y_{U I}-y_{-U I}$ is the income difference during unemployment between eligible and ineligible workers, and $\rho$ is the marginal propensity to consume (MPC) out of government benefits during unemployment. Expression (7) allows us to estimate, for a given level of risk aversion, the minimum MPC required for a net positive social welfare.

\section{Ignoring Non-UI Social Benefits Substitution}

The above welfare derivative assumes that the social planner is aware of the response in nonUI program benefits to changing UI eligibility. To highlight the importance of accounting for this response in determining the optimal eligibility threshold, we now derive the welfare impact assuming that there is no such response. That is, the social planner will wrongly assume that the level of non-UI social benefits $\left(g_{-U I}\right)$ stays the same when an ineligible worker becomes eligible for UI benefits.

The critical difference from the above case is that government budget constraint becomes

$$
F(G)\left(1-s_{-U I}\right) g_{-U I}+[1-F(G)]\left(1-s_{U I}\right)\left(b+g_{-U I}\right)=\breve{\tau}\left(F(G) s_{-U I}+[1-F(G)] s_{U I}\right)
$$

Taking the derivative of $\breve{\tau}$ with respect to $G$,

$$
\begin{aligned}
\frac{\partial \breve{\tau}}{\partial G}= & f(G) \frac{\left(1-s_{-U I}\right) g_{-U I}-\left(1-s_{U I}\right)\left(b+g_{-U I}\right)}{F(G) s_{-U I}+[1-F(G)] s_{U I}} \\
& -\frac{f(G)\left(s_{-U I}-s_{U I}\right) \breve{\tau}}{F(G) s_{-U I}+[1-F(G)] s_{U I}}
\end{aligned}
$$

Plugging this expression back into (3) we have:

$$
-\frac{d W}{d G} \approx f(G)\left(1-s_{-U I}\right)\left[u\left(c_{U I}^{u}\right)-u\left(c_{-U I}^{u}\right)\right]
$$




$$
-u^{\prime}\left(c^{e}\right) f(G)\left[\left(1-s_{U I}\right)\left(b+g_{-U I}\right)-\left(1-s_{-U I}\right) g_{-U I}+\left(s_{-U I}-s_{U I}\right) \tilde{\tau}\right]
$$

Further scaling the welfare gain by the welfare equivalent of an increased dollar of consumption for the marginal worker, $f(G) u^{\prime}\left(c^{e}\right)$,

$$
\begin{aligned}
-\frac{d \tilde{W}}{d G} \equiv-\frac{\frac{d W}{d G}}{f(G) u^{\prime}\left(c^{e}\right)} \approx & \left(1-s_{-U I}\right)\left(c_{U I}^{u}-c_{-U I}^{u}\right)\left(1+R \frac{\Delta c}{c^{e}}\right) \\
& -\left[\left(1-s_{U I}\right)\left(b+g_{-U I}\right)-\left(1-s_{-U I}\right) g_{-U I}+\left(s_{-U I}-s_{U I}\right) \tilde{\tau}\right] \\
= & \left(1-s_{-U I}\right)\left(c_{U I}^{u}-c_{-U I}^{u}\right)\left(1+R \frac{\Delta c}{c^{e}}\right) \\
& -\left[\left(1-s_{U I}\right)\left(b+g_{U I}\right)-\left(1-s_{-U I}\right) g_{-U I}+\left(s_{-U I}-s_{U I}\right) \tau\right] \\
& -\left(1-s_{U I}\right)\left(g_{-U I}-g_{U I}\right)\left[1+\frac{[1-F(G)]\left(s_{-U I}-s_{U I}\right)}{F(G) s_{-U I}+[1-F(G)] s_{U I}}\right](8)
\end{aligned}
$$

The difference between (6) and (8) is given by the last line. Since non-UI spending is actually lower for the UI-eligible worker due to program substitution, the planner will overstate the cost of expanding eligibility. The magnitude of the overstatement is equal to the mechanical difference in non-UI benefit outlays between the UI eligible and ineligible, as well as a term that reflects a larger impact of increased unemployment durations. As noted above, the social impact of UI on durations is scaled by overall government spending - the more the government spends, the more consequential the loss in tax revenues due to changes in unemployment durations becomes (Lawson, 2017). Therefore, not accounting for benefit substitution will overstate government spending, which overstates the impact of longer UI durations.

\section{Ignoring All Non-UI Programs}

Finally, we consider case in which the social planner ignores all non-UI programs in the government budget constraint:

$$
[1-F(G)]\left(1-s_{U I}\right) b=\stackrel{\imath}{\tau}\left(F(G) s_{-U I}+[1-F(G)] s_{U I}\right)
$$


Following the analogous steps as above, the welfare derivative becomes

$$
\begin{aligned}
-\frac{d \tilde{W}}{d G} \approx & \left(1-s_{-U I}\right)\left(c_{U I}^{u}-c_{-U I}^{u}\right)\left(1+R \frac{\Delta c}{c^{e}}\right) \\
& -\left[\left(1-s_{U I}\right) b+\left(s_{-U I}-s_{U I}\right) \stackrel{\imath}{\tau}\right] \\
= & \left(1-s_{-U I}\right)\left(c_{U I}^{u}-c_{-U I}^{u}\right)\left(1+R \frac{\Delta c}{c^{e}}\right) \\
& -\left[\left(1-s_{U I}\right)\left(b+g_{-U I}\right)-\left(1-s_{-U I}\right) g_{-U I}+\left(s_{-U I}-s_{U I}\right) \tilde{\tau}\right] \\
& +\left(s_{-U I}-s_{U I}\right)\left[g_{-U I}+\frac{F(G)\left(1-s_{-U I}\right) g_{-U I}+[1-F(G)]\left(1-s_{U I}\right) g_{-U I}}{F(G) s_{-U I}+[1-F(G)] s_{U I}}\right]
\end{aligned}
$$

Equation (9) shows that ignoring all programs will have two impacts on the social cost calculation. First, it ignores the potential savings from lowered spending on non-UI programs, overstating costs, as it the previous case. However ignoring all non-UI spending leads to a smaller overall government budget, which diminishes the importance of search distortions. Therefore, there is an ambiguous impact on the cost calculation.

\section{C.1 Calibration}

The upper panel of Table 6 summarizes the quantities we use to calibrate the model. Each empirical quantity (earnings, UI and non-UI benefits, and nonemployment durations) are estimated for UI-eligible and ineligible workers at the threshold by taking the upper and lower estimated intercepts of Equations (1) and (2), where the dependent variables are earnings, benefits, or durations. For each outcome, the quantities $\hat{\beta}_{0}+\hat{\tau}_{y}+\left(1-\hat{\alpha}_{0}-\hat{\tau}_{d}\right) \hat{\tau}$ and $\hat{\beta}_{0}-\hat{\alpha}_{0} \hat{\tau}$ correspond to the UI-eligible and ineligible, respectively. Note that these are the

upper and lower reduced form intercepts, $\hat{\beta}_{0}+\hat{\tau}_{y}$ and $\hat{\beta}_{0}$, with an adjustment factor. The adjustment factors are necessary because not every claimant above the threshold are eligible for UI and not every claimant below the threshold is ineligible. The terms $\left(1-\hat{\alpha}_{0}-\hat{\tau}_{d}\right) \hat{\tau}$ and $-\hat{\alpha}_{0} \hat{\tau}$ mechanically "sharpen" the first stage, so that the difference is exactly the fuzzy RD estimate. To the left of the threshold, the probability of eligibility is $\hat{\alpha}_{0}=0.11$, whereas the probability to the right of the threshold is $\hat{\alpha}_{0}+\hat{\tau}_{d}=0.60$.

In our base case, we assume that workers consume their incomes. When a worker is employed, she consumes out of earnings, and when unemployed, she consumes out of UI and 
means-tested program benefits. Therefore, we estimate consumption during employment, $c^{e}$, with earnings in the quarter right before layoff. As shown in Panel $\mathrm{C}$ of Figure 7, the estimated intercepts are quite similar for those who are and are not eligible for UI. In the calibration, we use an average of the two: $c^{e}=1795.14$. For consumption while unemployed, we use estimated UI and non-UI (i.e., TANF and SNAP) benefits in the quarter immediately following the UI claim, which gives $c_{U I}^{u}=1535.19$ and $c_{-U I}^{u}=538.47 .^{13}$

We calculate the time spent unemployed, $1-s_{-U I}$ and $1-s_{U I}$, using the estimated durations of initial nonemployment spells, as measured by the number of consecutive quarters without earnings. In the data, we find that the average duration for a workers right below the threshold is 2.47 quarters and that UI eligibility increases the duration by 0.57 quarters. Since $1-s_{U I}$ and $1-s_{-U I}$ are expressed as proportions of time spent unemployed, we divide the duration by 10 quarters, which is where we truncate durations, so that $1-s_{U I}=0.30$ and $1-s_{-U I}=0.24$. The proportions of time spent employed, $s_{U I}=0.70$ and $s_{-U I}=0.76$ roughly translate to 22 months of employment, which is close to the observed pre-layoff job tenure among workers near the RD threshold (Table 1).

Finally, for the lump sum tax $\tau$, we need $F(G)$, the proportion of workers eligible for UI. We use the fact that approximately 10 percent of claimants have earnings below the earnings threshold, and the probability of eligibility is about 0.11 below the threshold and 0.60 above the threshold. When we calibrate (5), we assume that worker's utility is given by a CRRA utility function: $u(c)=\frac{c^{1-\gamma}}{1-\gamma}$, where $\gamma \in[1,4]$, as in Gruber (1997). For calibrating the expression (6), we simply use coefficient of relative risk aversion $(R)$ ranging from 1 to 4.

We have assumed so far that workers consume out of their individual income. However, if most workers are part of two-earner households, using individual income may overstate the drop in consumption during unemployment, which will overstate the consumption smoothing benefits of UI. While we do not observe households in our data, we can ballpark

\footnotetext{
${ }^{13}$ Using the intercept adjustment method described above, we still find a positive UI benefit for ineligible workers of about $\$ 70$ per quarter. For the calibration, we treat this amount as "non-UI" spending, and adjust the benefits for eligible workers the same amount so that the difference is equal to the RD estimate.
} 
the consumption smoothing benefits of UI within households by assuming that households comprise of two workers that both make the same amount when employed. In this case, consumption during employment is $c^{e}=3590.28$. When one household member becomes unemployed, income drops to $c_{U I}^{u}=3330.33$ or $c_{-U I}^{u}=2333.61$, which is the sum of UI benefits, non-UI benefits, and the working spouse's earnings. This exercise assumes that spousal earnings do not respond when one member of the household becomes unemployed, which approximates the negligible to small effects found in the literature (e.g., Rothstein and Valletta, 2014, Ganong and Noel, 2017); and that spousal earnings do not respond to UI eligibility, which is more contentious, as Cullen and Gruber (2000) find that wives have large labor supply responses to husbands' UI benefits, but Kawano and LaLumia (2014) do not.

The bottom panel of Table 6 contains the results of our calibration exercise. In the first three columns, we report the consumption smoothing benefits under different assumptions about utility functions and consumption levels. As expected, consumption smoothing benefits are smaller for lower levels of risk aversion and when we account for other income in the household. Columns (4) - (6) show the social costs under different assumptions on non-UI spending. We find that when we ignore the benefit substitution, costs are overstated by approximately 6 percent. When we ignore all non-UI programs, the cost decreases. Comparing the social benefits and social costs of expanding eligibility, we find that it is optimal to expand eligibility at all levels of risk aversion when we consider only individual incomes. When we consider household incomes, we find that it is optimal to expand eligibility when the coefficient of relative risk aversion is above 1.33. In the final two columns, we do not assume that workers consume all of their incomes, and instead report the minimum marginal propensity to consume out of government benefits (MPC) in order for it to be welfare-enhancing to expand eligibility. At a coefficient of relative risk aversion of 1 , the MPC must be at least 0.86 , while for a risk aversion parameter of 4 , workers must have at least an MPC of 0.39 . 
Figure A.1: UI Monetary Eligibility Requirements, 2010

A. Distribution of Simulated Eligibility Measure

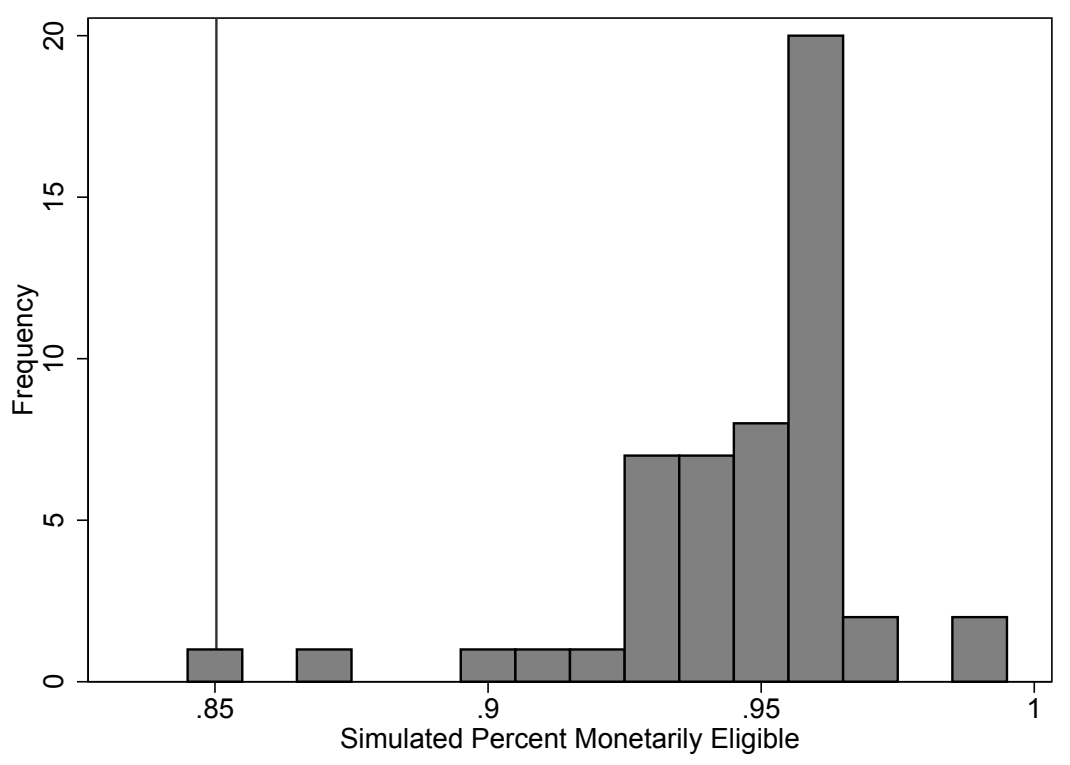

B. Relationship Between Simulated Eligibility Measure and State Average Annual Earnings

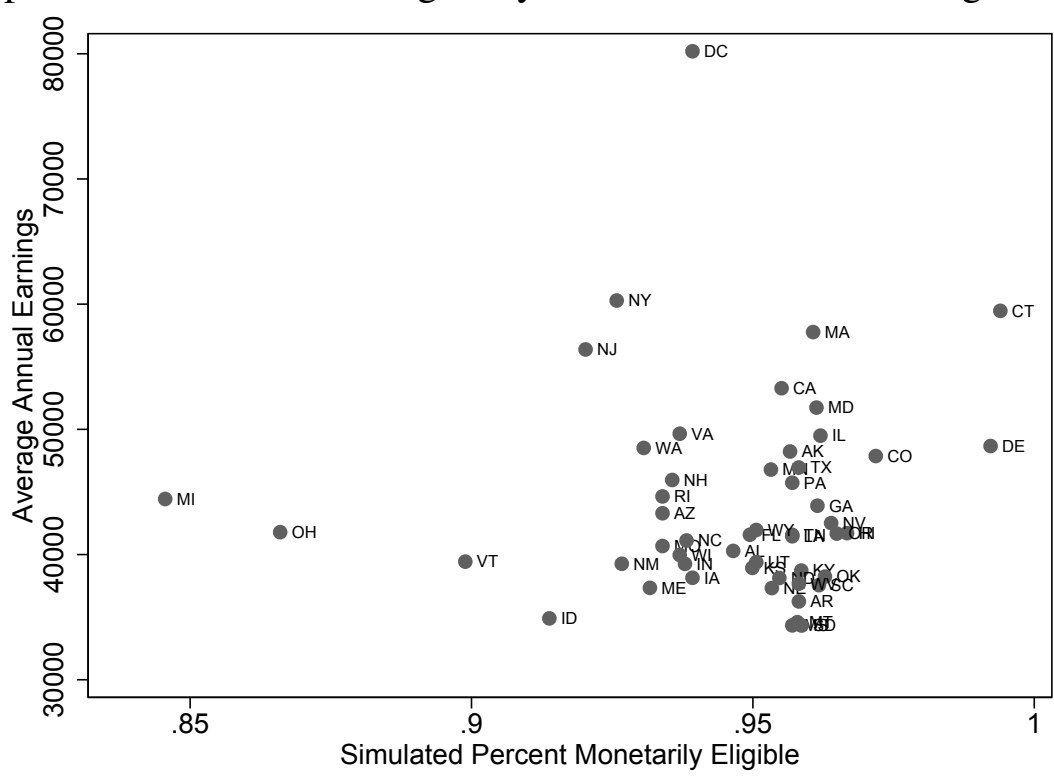

Notes: Panel A shows the distribution of a simulated state eligibility measure described in Appendix Section B.4. Vertical line denotes MI's simulated eligibility measure. Panel B shows how these eligibility measures correlate with average annual earnings in 2010. The average annual earnings data is from the Quarterly Census of Employment and Wages. 
Figure A.2: Comparison of U.S. and Michigan Labor Markets

A. Unemployment Rates

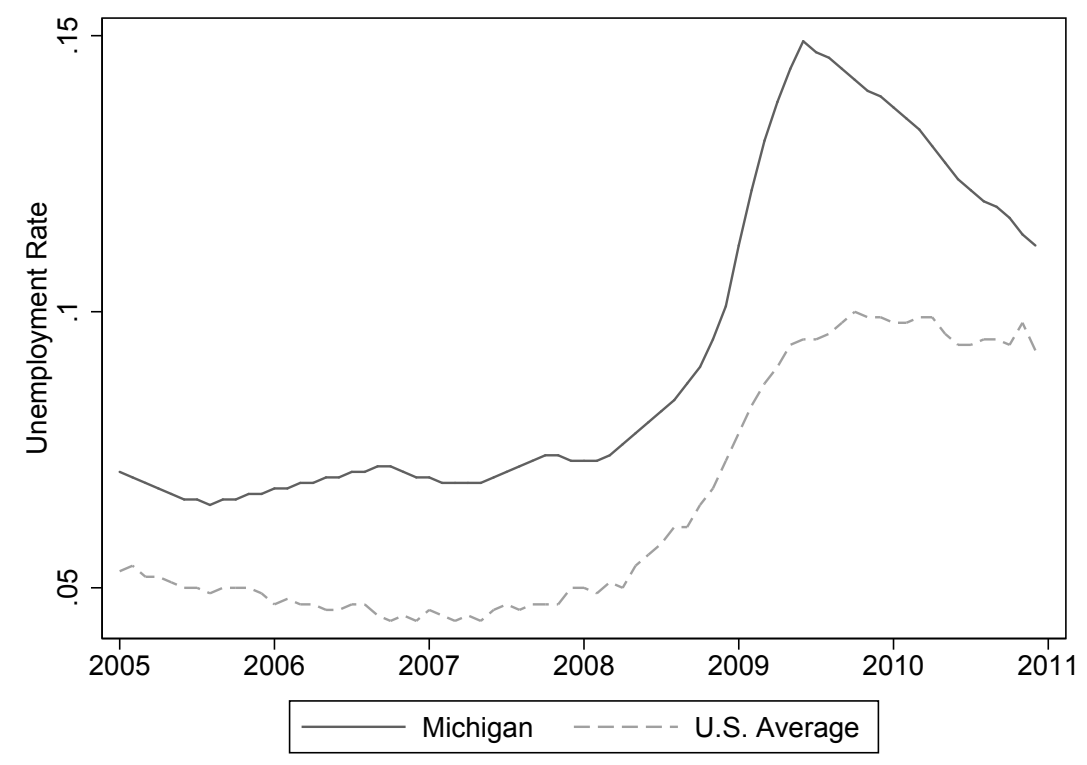

B. Extended Benefits Available

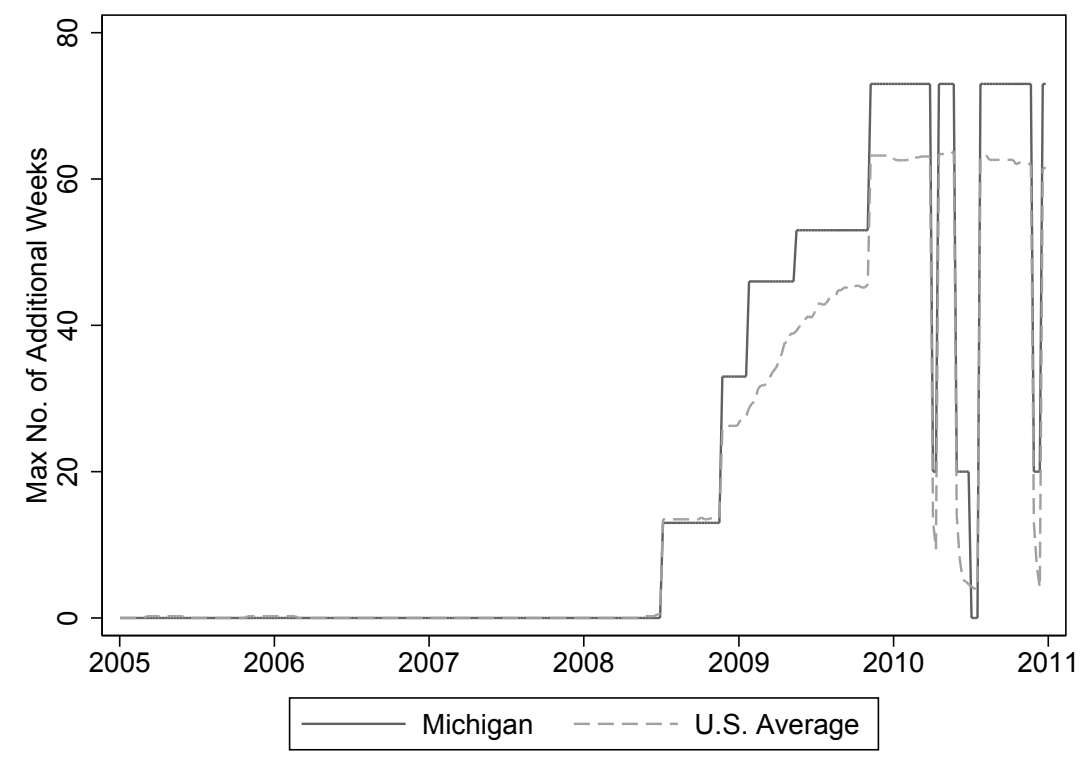

Notes: Panel A shows the official unemployment rates over time in Michigan and the entire U.S. Data is from the Bureau of Labor Statistics. Panel B shows the statutory maximum number of weeks of extended benefits available, including benefits from the Extended Benefits (EB) and Emergency Unemployment Compensation (EUC08) programs. Data source is U.S. Department of Labor (DOL), Extended Benefits Trigger Notice 20052011 and U.S. DOL, Emergency Unemployment Compensation Trigger Notice, 2005-2011. 
Figure A.3: Relationship Between UI Benefits and Means-Tested Programs in U.S., 2010
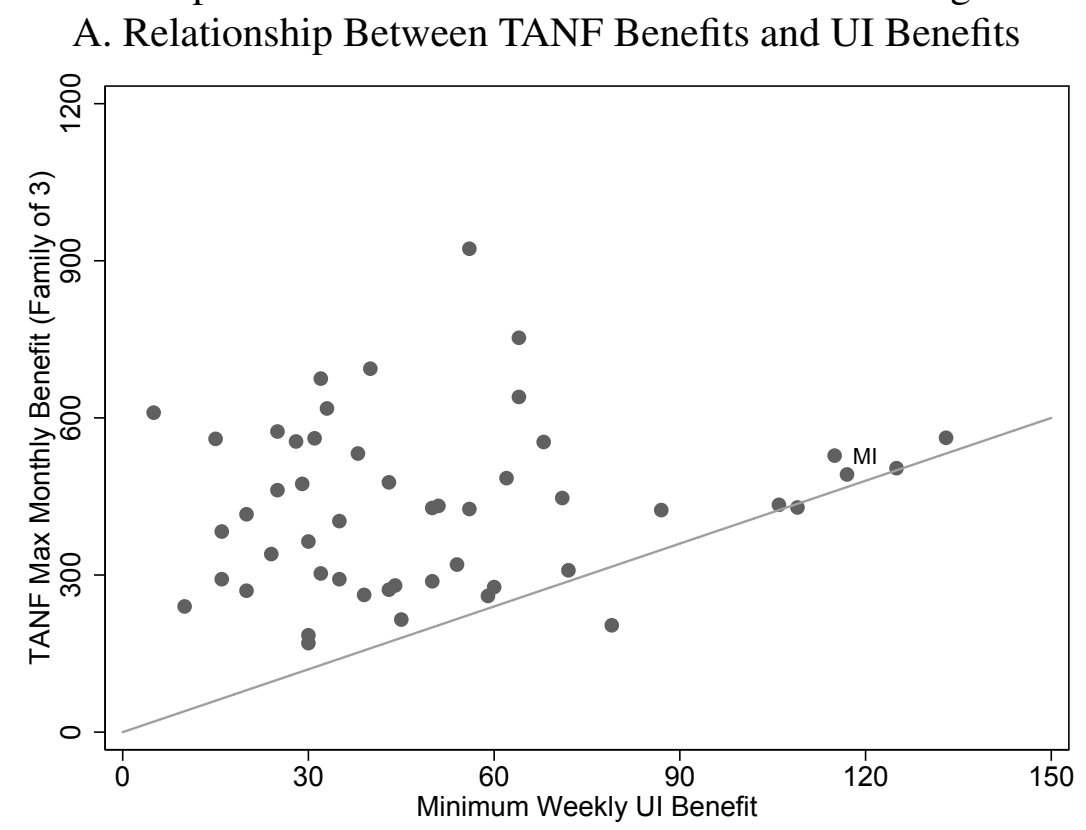

B. Relationship Between Medicaid Income Thresholds and UI Benefits

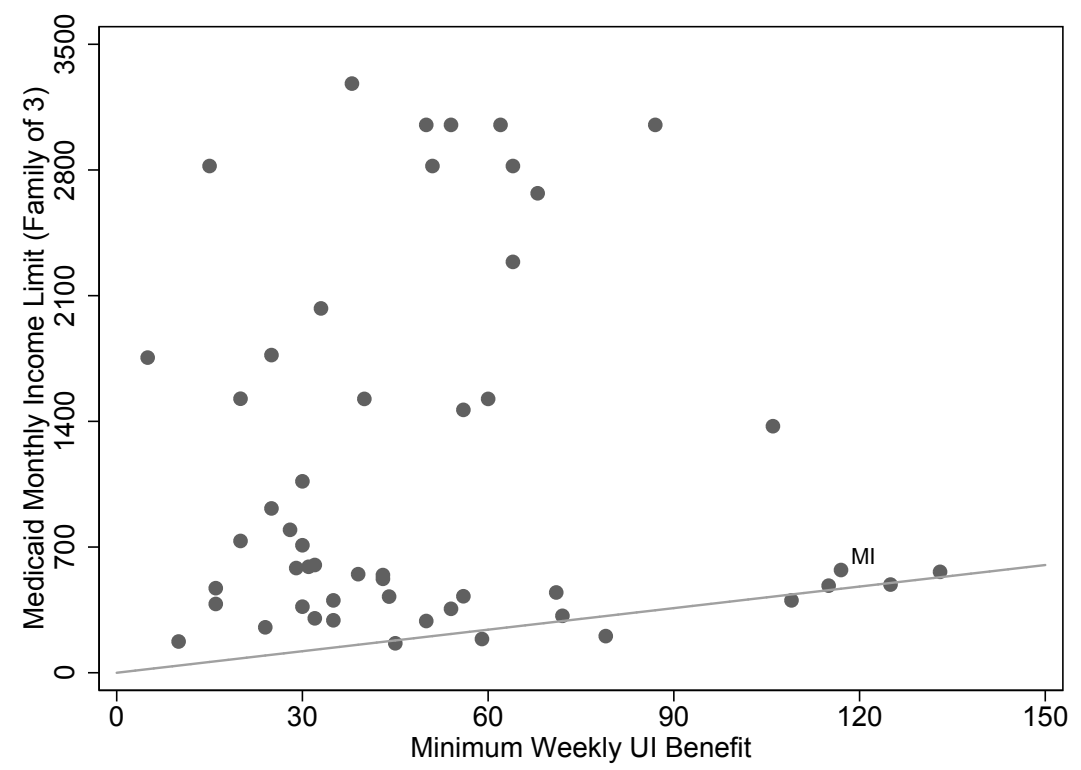

Notes: Panel A shows the relationship between the minimum weekly UI benefit in each state and the TANF benefit guarantee for a family of three in 2010. Panel B shows the relationship between the minimum weekly UI benefit in each state and the monthly income limit (family of three) for parental Medicaid at the end of 2009. Data is from U.S. DOL, Comparison of State Unemployment Laws 2010; Urban Institute, Welfare Rules Databook 2010; and Kaiser Family Foundation, Findings of a 50 State Survey of Eligibility Rules, Enrollment and Renewal Procedures, and Cost-Sharing Practices in Medicaid and CHIP for Children and Parents During 2009, December 2009. Solid lines in both graphs denote the points where the minimum UI benefit is equal to the TANF benefit guarantee or Medicaid income limit. 
Figure A.4: RD Estimates on TANF Participation Over Time: By Potential Duration

A. Short Potential Duration

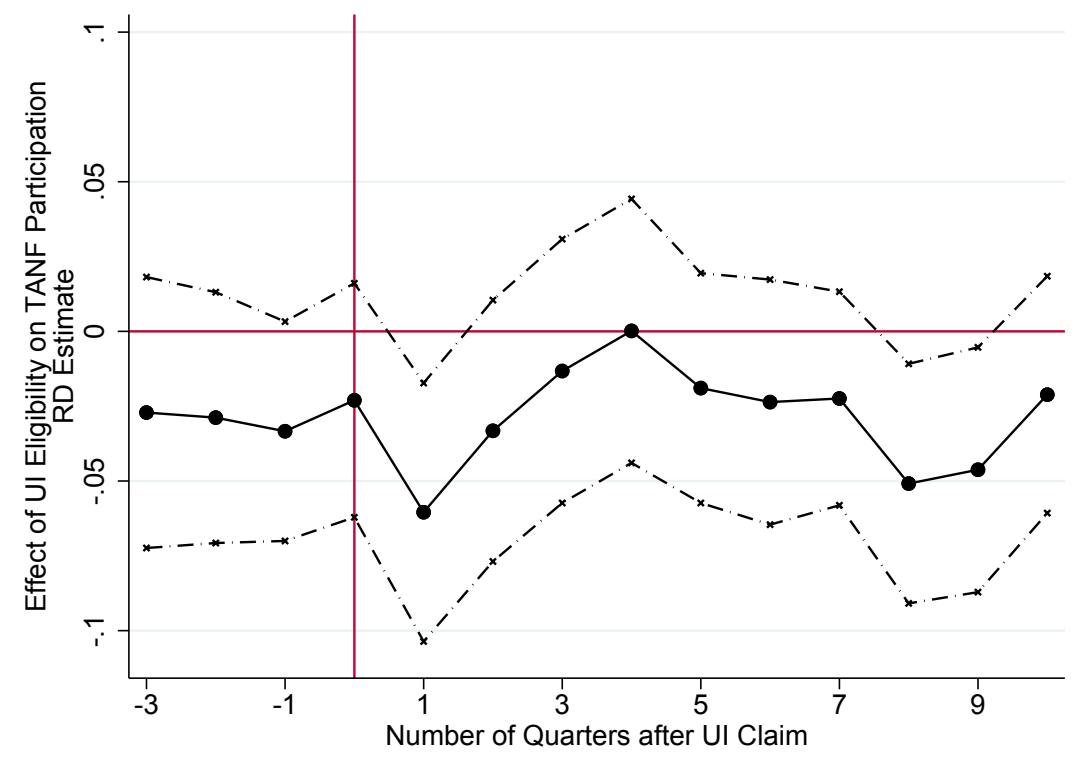

\section{B. Long Potential Duration}

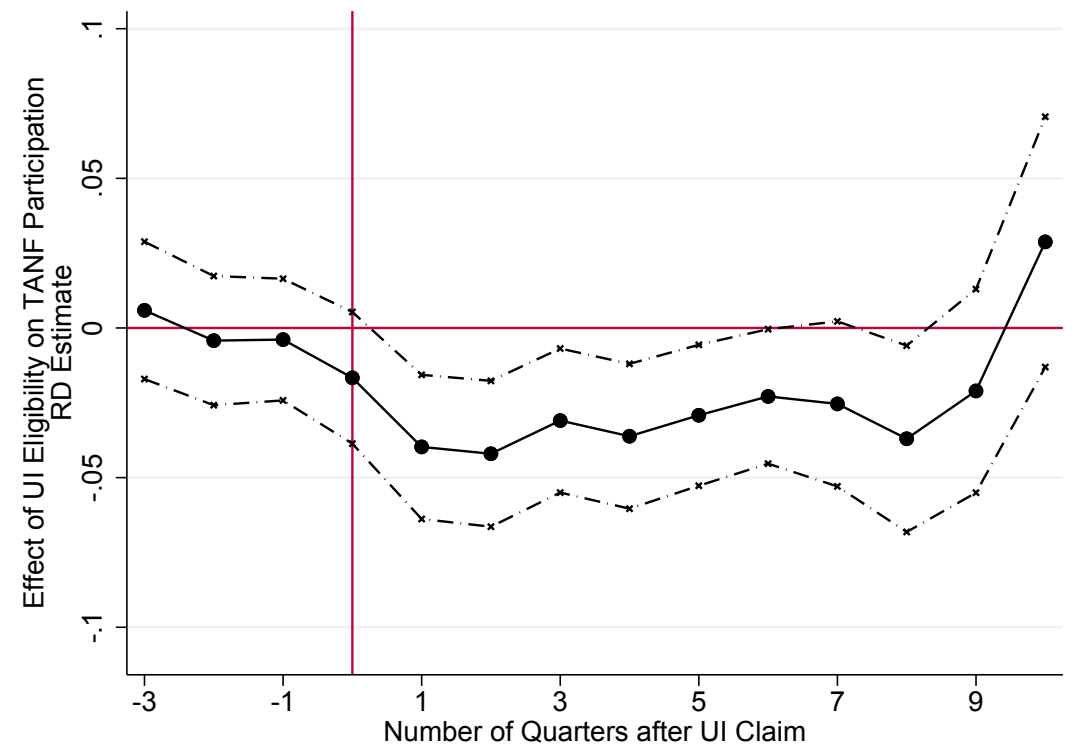

Notes: This figure plots fuzzy RD estimates of the effect of UI eligibility on probability of TANF participation in a certain quarter relative to the claim quarter. Panel A restricts to claims made before 2008 and Panel B restricts to claims made between September 21, 2008 and May 15, 2010. Each RD estimate is the ratio of coefficients on an indicator for being above the minimum earnings threshold in local linear first stage and reduced form regressions. The first stage (reduced form) specifications regress an indicator for UI eligibility (indicator for TANF participation) on a constant, normalized high quarter earnings, an indicator for being above the minimum earnings threshold, and their interaction. Each estimate uses the Calonico, Cattaneo and Titiunik (2014) bandwidth and is bias-corrected. The dash-dot lines denote robust 95 percent confidence intervals. 
Figure A.5: TANF Participation in Various Quarters Relative to Claim Filing
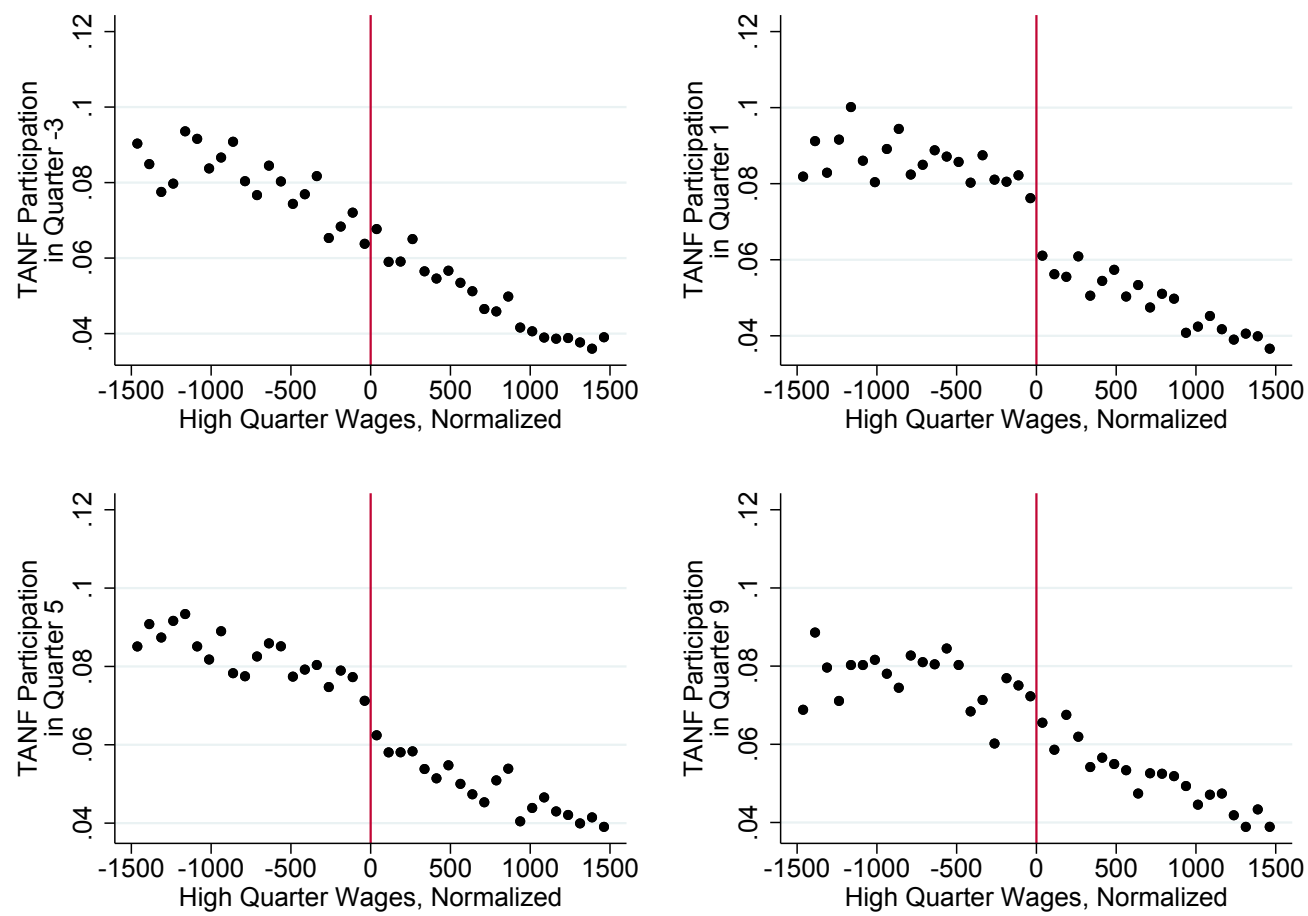

Notes: These figures plot the fraction of UI claimants who received TANF benefits three quarters before the initial UI claim filing, and the first, fifth, and nineth quarter after claim filing for each non-overlapping \$75 bin of (normalized) high quarter earnings. The vertical lines denote the minimum earnings threshold. 
Figure A.6: SNAP Participation in Various Quarters Relative to Claim Filing
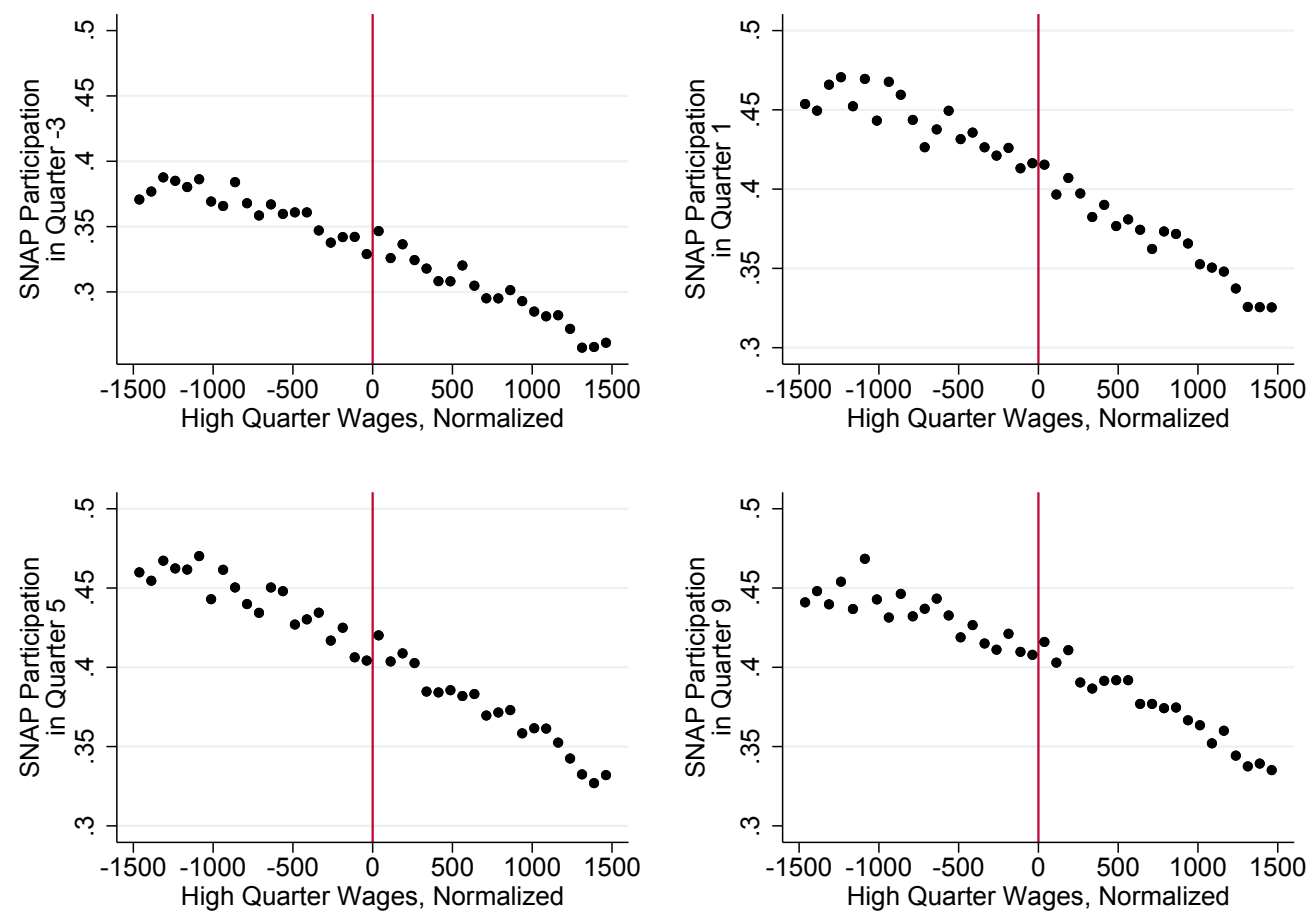

Notes: These figures plot the fraction of UI claimants who received SNAP benefits three quarters before the initial UI claim filing, and the first, fifth, and nineth quarter after claim filing for each non-overlapping $\$ 75$ bin of (normalized) high quarter earnings. The vertical lines denote the minimum earnings threshold. 
Figure A.7: Medicaid Participation in Various Quarters Relative to Claim Filing
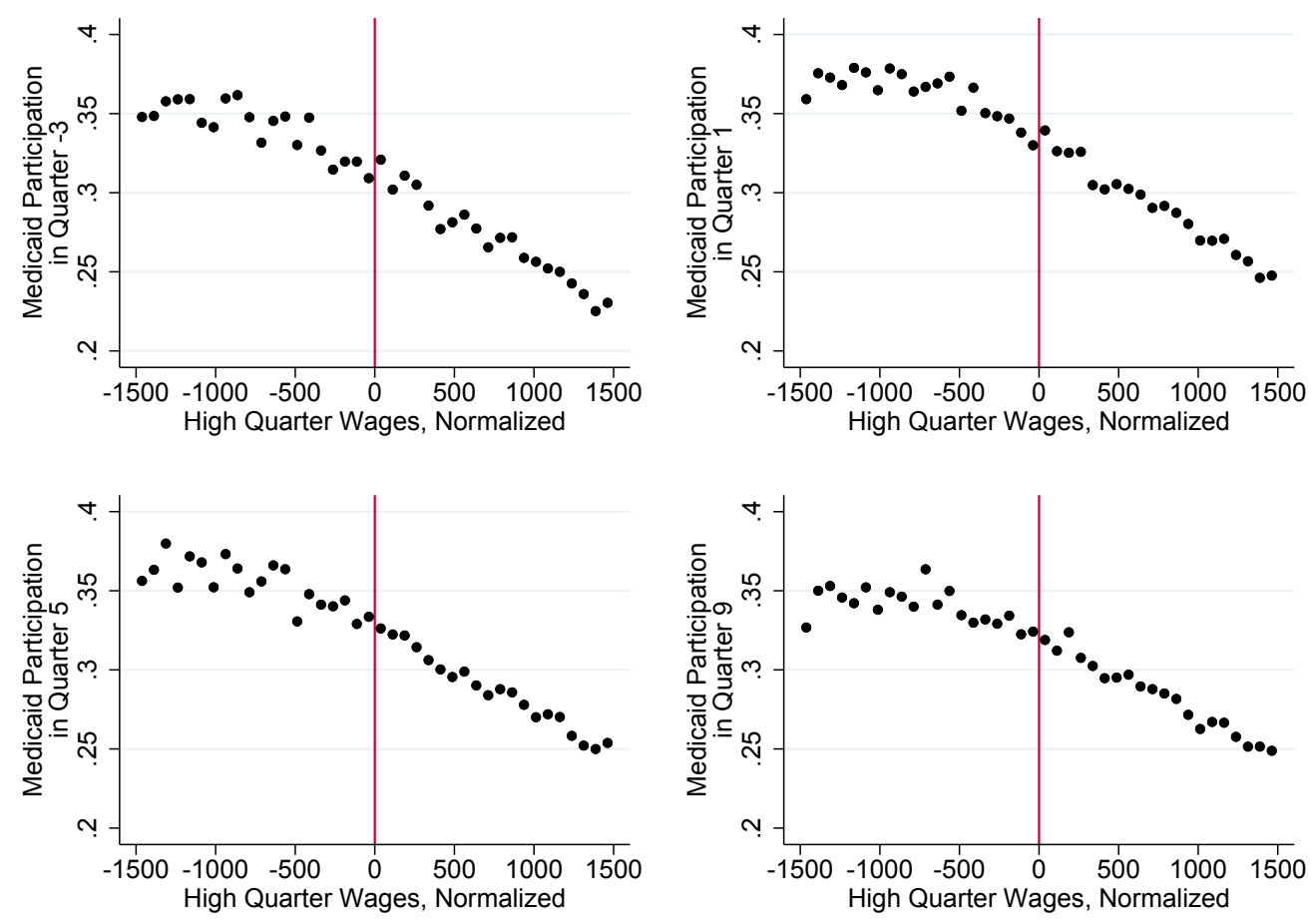

Notes: These figures plot the fraction of UI claimants who enrolled in Medicaid three quarters before the initial UI claim filing, and the first, fifth, and nineth quarter after claim filing for each non-overlapping $\$ 75$ bin of (normalized) high quarter earnings. The vertical lines denote the minimum earnings threshold. 
Figure A.8: Employment Effects Over Time

A. Probability Employed

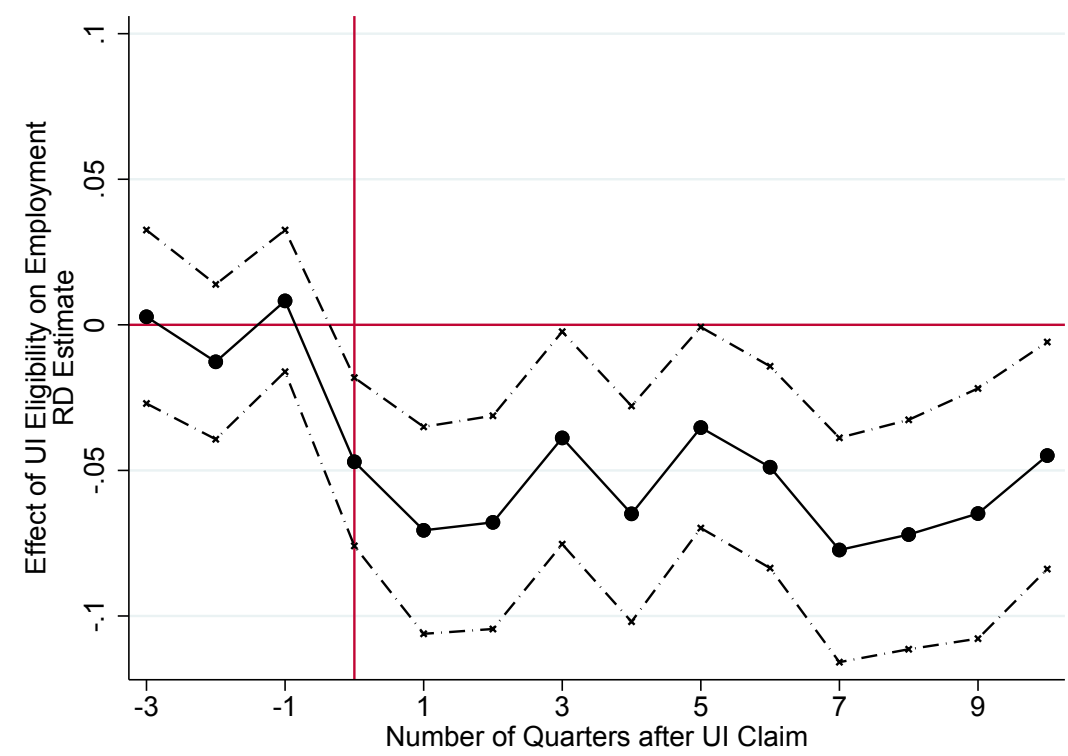

B. Hazard from Nonemployment

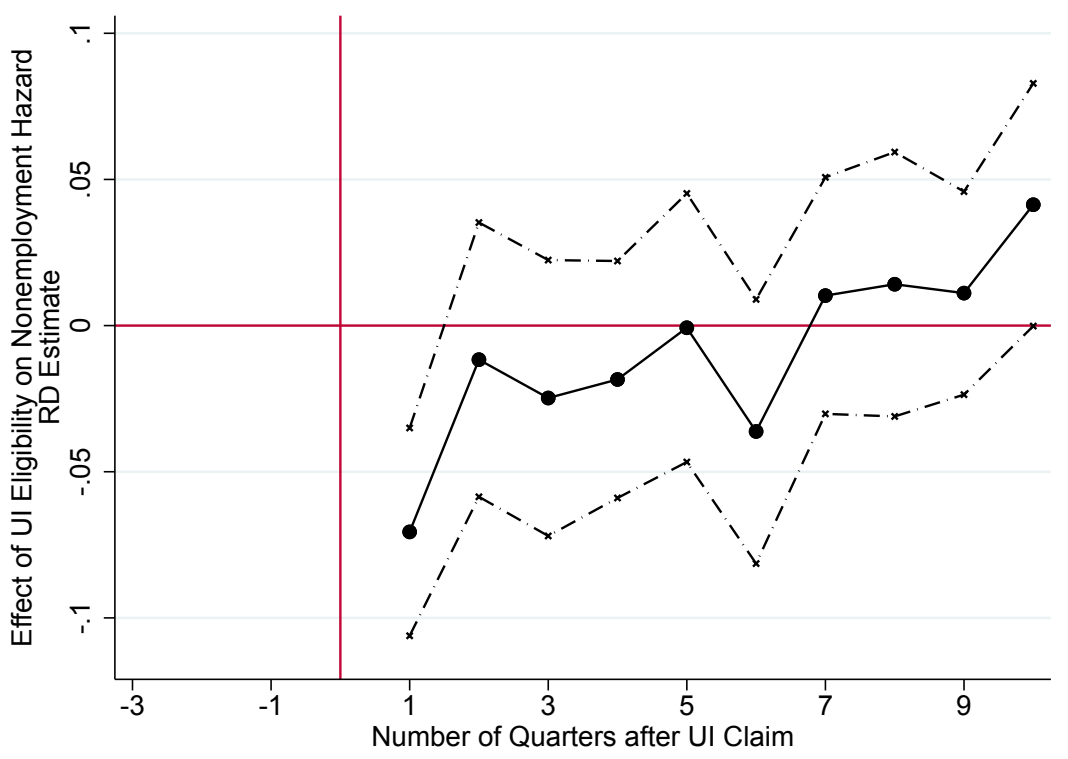

Notes: These figures plot fuzzy RD estimates of the effect of UI eligibility on probability of having positive earnings (panel A) or exiting nonemployment (panel B) in a certain quarter relative to the initial UI claim quarter. Each RD estimate is the ratio of coefficients on an indicator for being above the minimum earnings threshold in local linear first stage and reduced form regressions. The first stage (reduced form) specifications regress an indicator for UI eligibility (indicator for having positive earnings or exiting nonemployment) on a constant, normalized high quarter earnings, an indicator for being above the minimum earnings threshold, and their interaction. Each estimate uses the Calonico, Cattaneo and Titiunik (2014) bandwidth and is biascorrected. The dash-dot lines denote robust 95 percent confidence intervals. 
Figure A.9: Effects by Metro Area Unemployment Rate

\section{A. TANF}

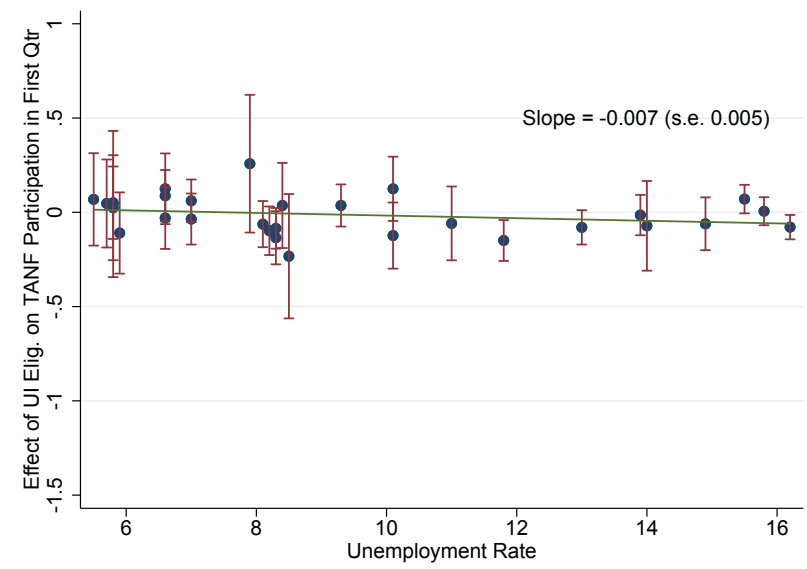

B. SNAP

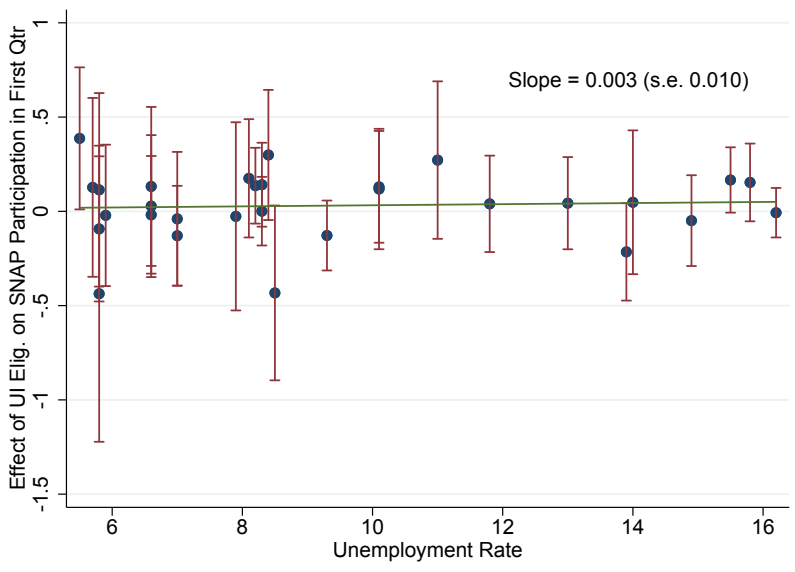

\section{Medicaid}

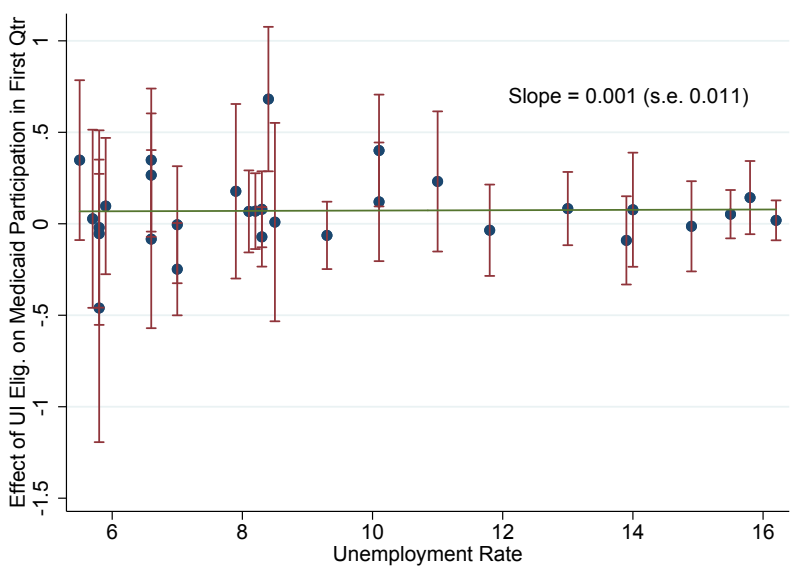

Notes: These figures plot fuzzy RD estimates of the effect of UI eligibility on the probability of participating in a means-tested program in the first quarter after UI claiming for each major county-year, against the county-year unemployment rate. The counties are Kent, Macomb, Oakland, Wayne, Genesee; the years cover 2005-2010. Each RD estimate is the ratio of coefficients on an indicator for being above the minimum earnings threshold in local linear first stage and reduced form regressions. The first stage (reduced form) specifications regress an indicator for UI eligibility (participation in a program one quarter after layoff) on a constant, normalized high quarter earnings, an indicator for being above the minimum earnings threshold, and their interaction. Each estimate uses the Calonico, Cattaneo and Titiunik (2014) bandwidth and is bias-corrected. The vertical lines denote robust 95 percent confidence intervals. Horizontal lines are linear fits of the estimates. 
Figure A.10: Characteristics of UI Ineligible Workers Across States

A. TANF

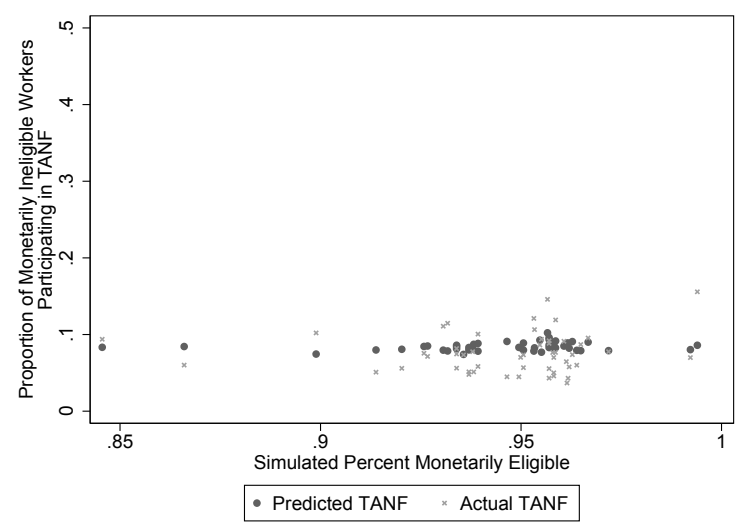

B. SNAP

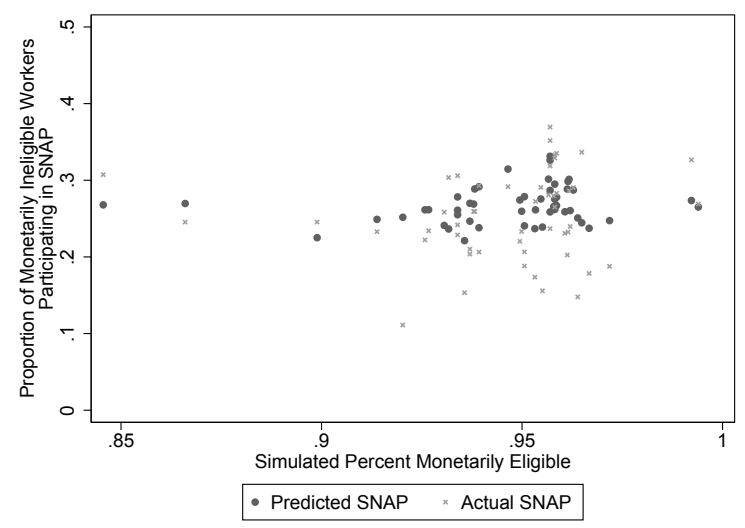

\section{Medicaid}

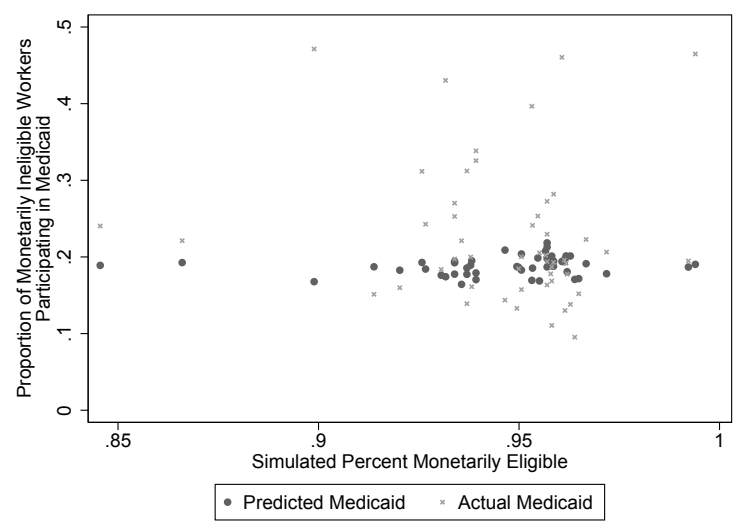

Notes: This figure shows how the characteristics of workers who are likely to be monetarily ineligible varies with the state's monetary eligibility requirements (black dots). The dependent variable is constructed by predicting the probability of participation in each means-tested program using worker demographic and industry characteristics (see Appendix Section B.5 for details). The mean predicted probability of participation among likely ineligible workers in each state is plotted against the simulated eligibility measure described in Appendix Section B.4. For reference, the proportion of likely monetarily ineligible workers who are actually on each program is also plotted (gray dots). 


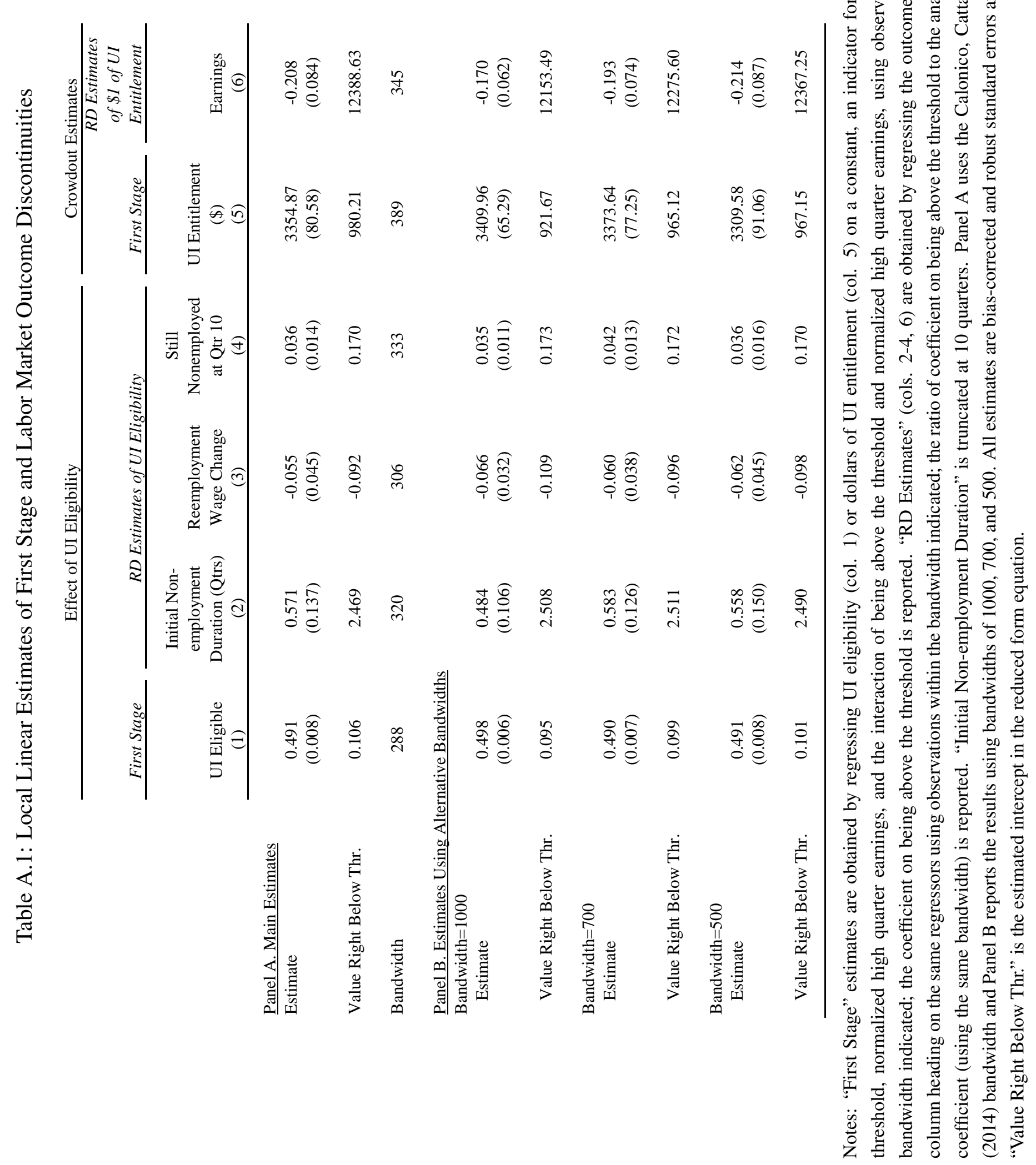




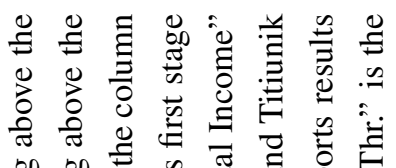

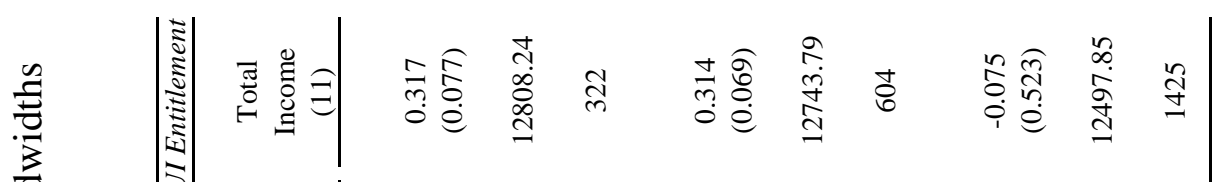

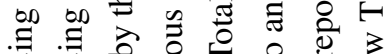

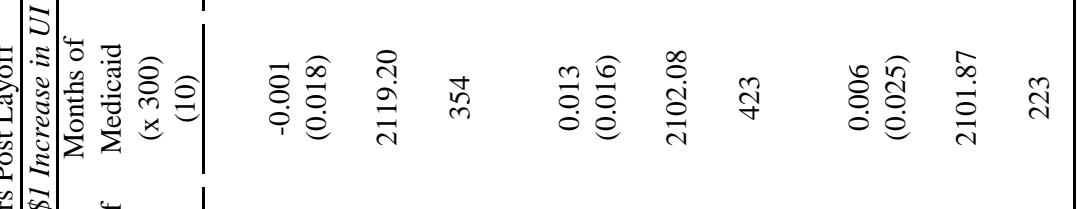

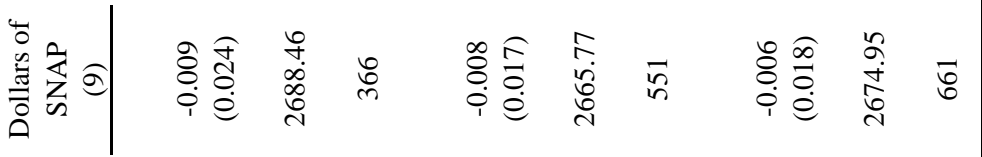

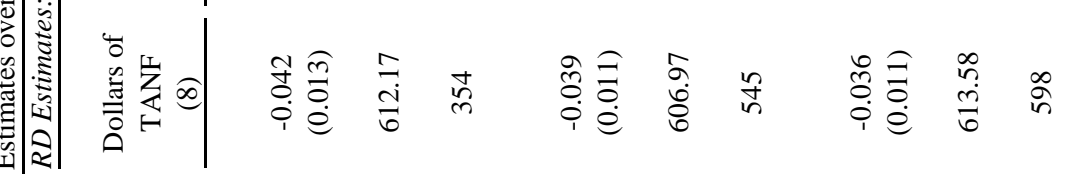

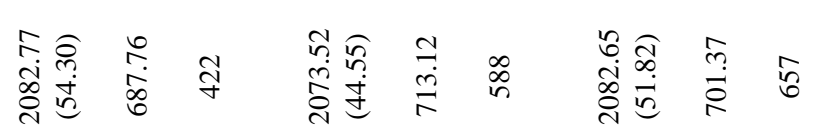

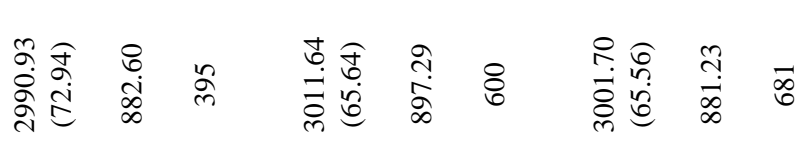

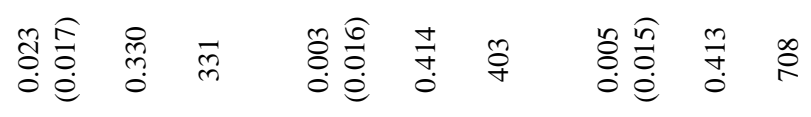

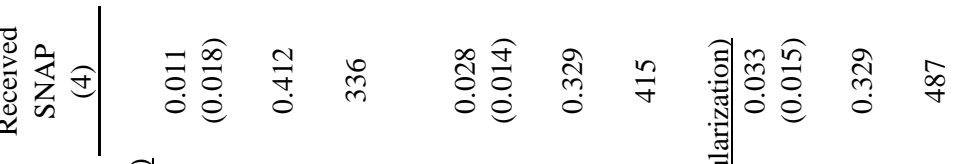
逗

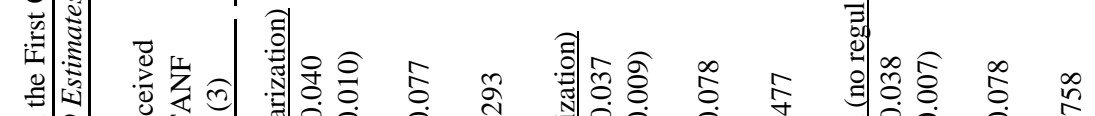

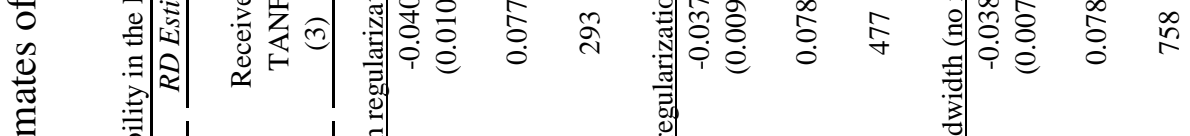

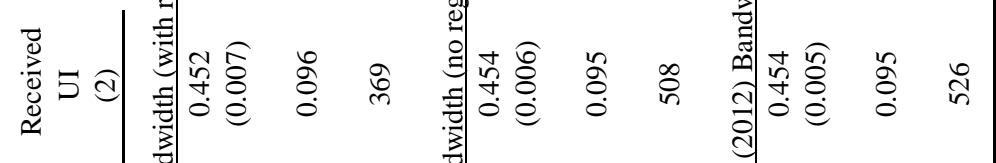

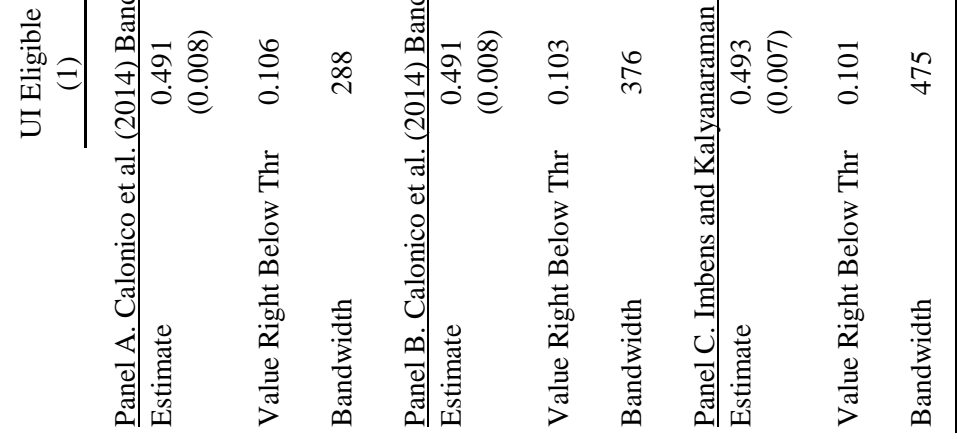

总

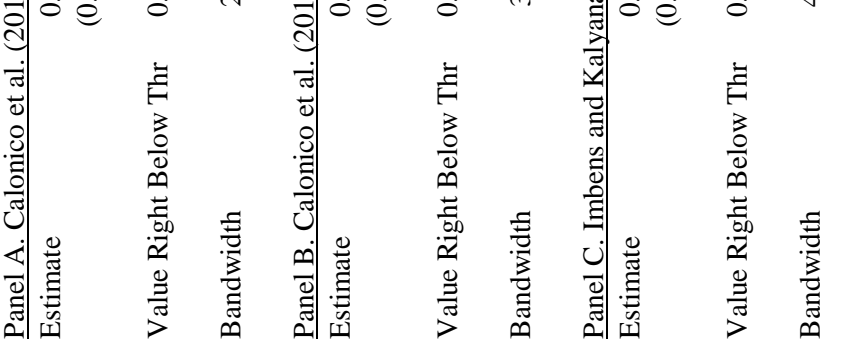




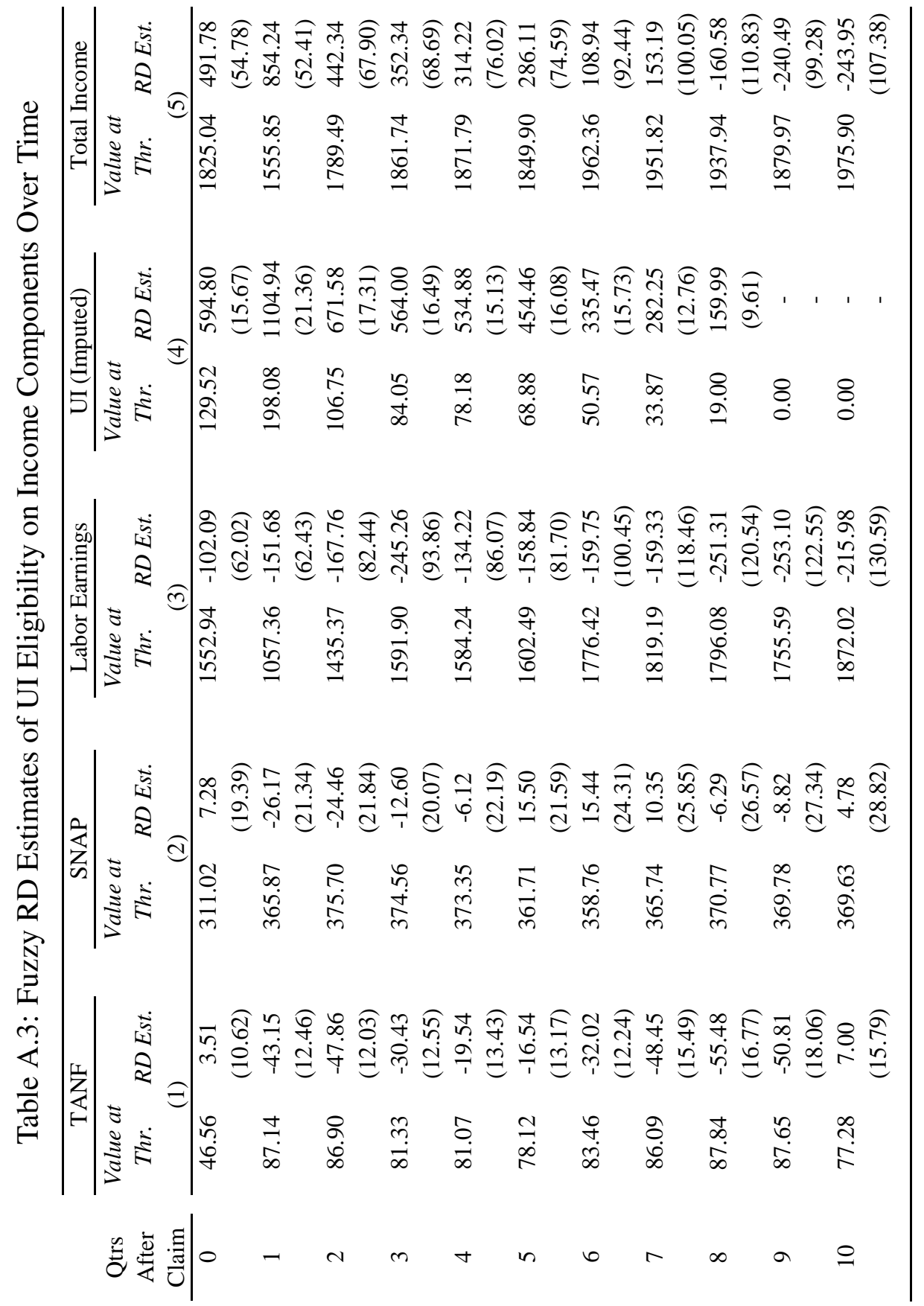


Table A.4: Characteristics of Workers at Alternative Thresholds

\begin{tabular}{|c|c|c|c|}
\hline \multirow{3}{*}{ Demographic Characteristics } & \multicolumn{3}{|c|}{ Sample } \\
\hline & \multirow[t]{2}{*}{$\begin{array}{c}\text { Minimum Earnings } \\
\text { Threshold (RD) } \\
\text { (within \$1500 of thrs) } \\
(1) \\
\end{array}$} & \multirow[t]{2}{*}{$\begin{array}{c}\text { Earnings Distribution } \\
\text { Threshold (RD) } \\
\text { (within } 0.5 \text { of thrs) } \\
\text { (2) } \\
\end{array}$} & \multirow[t]{2}{*}{$\begin{array}{c}\text { Maximum Benefit } \\
\text { Threshold (RKD) } \\
\text { (within \$1500 of thrs) } \\
\text { (3) }\end{array}$} \\
\hline & & & \\
\hline Female & $58.8 \%$ & $36.6 \%$ & $43.1 \%$ \\
\hline Age & 33.2 & 33.5 & 40.2 \\
\hline \multicolumn{4}{|l|}{ Education } \\
\hline Less Than HS & $18.3 \%$ & $18.0 \%$ & $10.0 \%$ \\
\hline High School & $50.5 \%$ & $49.4 \%$ & $52.6 \%$ \\
\hline Some College & $24.4 \%$ & $23.2 \%$ & $25.9 \%$ \\
\hline Bachelor Degree & $3.7 \%$ & $5.0 \%$ & $7.0 \%$ \\
\hline Advanced Degree & $2.6 \%$ & $3.2 \%$ & $4.4 \%$ \\
\hline \multicolumn{4}{|l|}{ Race } \\
\hline White & $51.7 \%$ & $52.8 \%$ & $64.0 \%$ \\
\hline Black & $19.5 \%$ & $15.3 \%$ & $10.9 \%$ \\
\hline Asian & $0.7 \%$ & $0.9 \%$ & $1.2 \%$ \\
\hline Native American/Alaskan & $1.5 \%$ & $1.7 \%$ & $0.9 \%$ \\
\hline Has Dependents & $25.9 \%$ & $23.7 \%$ & $26.6 \%$ \\
\hline \multicolumn{4}{|c|}{ Program Participation and Employment Before Layoff } \\
\hline Ever Claimed UI (since 2001) & $24.8 \%$ & $25.9 \%$ & $27.8 \%$ \\
\hline \multicolumn{4}{|l|}{ Ever Received Benefits from (since 2005)... } \\
\hline TANF & $15.0 \%$ & $10.3 \%$ & $2.3 \%$ \\
\hline SNAP/Food Stamps & $45.4 \%$ & $34.9 \%$ & $11.9 \%$ \\
\hline Medicaid & $41.5 \%$ & $29.4 \%$ & $9.1 \%$ \\
\hline Previous Job Tenure (Months) & 24.03 & 13.35 & 67.81 \\
\hline & [40.73] & [34.06] & [80.12] \\
\hline \multicolumn{4}{|l|}{ Previous Industry } \\
\hline Manufacturing & $4.7 \%$ & $12.8 \%$ & $29.6 \%$ \\
\hline Retail Trade & $22.9 \%$ & $11.3 \%$ & $9.4 \%$ \\
\hline Adminstration, Support and Waste & $13.9 \%$ & $22.4 \%$ & $8.4 \%$ \\
\hline Accomodation and Food Services & $25.6 \%$ & $9.1 \%$ & $2.9 \%$ \\
\hline Health Care and Social Assistance & $8.1 \%$ & $6.2 \%$ & $8.0 \%$ \\
\hline Previous Year Earnings & 8277.72 & 8247.71 & 32440.67 \\
\hline & {$[3960.09]$} & {$[3757.23]$} & {$[6954.54]$} \\
\hline Observations & 252,616 & 126,616 & 301,275 \\
\hline
\end{tabular}

Notes: The sample from column 1 consists of claims with high quarter earnings within $\$ 1500$ of the minimum earnings threshold, whose base period earnings are more than 1.5 times the high quarter earnings. Column 2 consists of claims for which the base period to high quarter earnings ratio is less than 2 and who have high quarter earnings above the minimum required for eligibility. Column 3 consists of claims with high quarter earnings within $\$ 1500$ of the maximum benefit threshold. In all three columns, claims are included if there were no previous initial claim in the previous two years. See Appendix Section B.1 for details. Standard deviations are in brackets. 
Table A.5: Heterogeneity of UI Eligibility Effect and Means of Threshold Characteristics

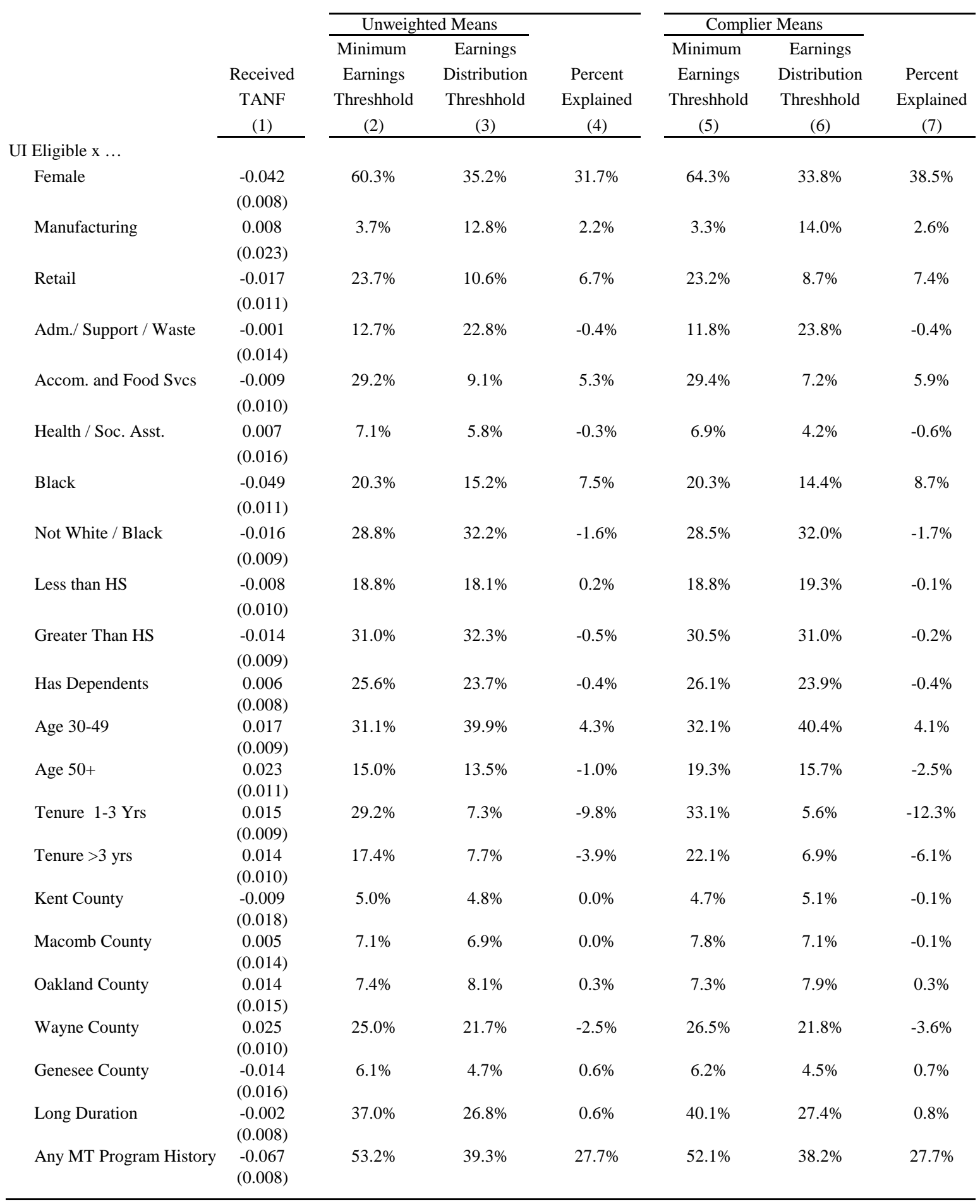

Notes: Column 1 contains estimated coefficients on the interaction between UI eligibility and various characteristics in a two-stage least squares regression of an indicator for TANF receipt in the first quarter after layoff on a constant, various characteristics, (norm.) high quarter earnings, the interaction of (norm.) high quarter earnings and being above the threshold, an indicator for being UI eligible, and being UI eligible interacted with the various characteristics, where UI elibility and UI eligibility interactions are instrumented with being above the threshold and interactions between being above the threshold and various characteristics. The bandwidth is $\$ 350$. Standard errors are in parentheses. Columns 2 and 3 contain the average characteristics of the minimum earnings threshold sample and the earnings distribution sample within $\$ 350$ and 0.5 of the thresholds, respectively. Columns 5 and 6 are the characterstics of each sample, weighted as in Abadie (2003). Columns 4 and 7 show the percent of the total difference in the effects of UI eligibility at each threshold explained by each charactersitic. 


\section{References}

Abadie, Alberto. 2003. "Semiparametric instrumental variable estimation of treatment response models." Journal of Econometrics, 113: 231-263.

Baily, Martin Neil. 1978. "Some Aspects of Optimal Unemployment Insurance." Journal of Public Economics, 10: 379-402.

Bureau of Labor Statistics. 1948-2015a. "Labor Force Statistics from the Current Population Survey: Unemployment Rate, Seasonally Adjusted - LNS14000000.” Accessed January 2016.

Bureau of Labor Statistics. 1976-2015b. "Local Area Unemployment Statistics Series: Michigan, Statewide, Seasonally Adjusted - LASST260000000000003, LASST260000000000004, LASST260000000000005, LASST260000000000006.”' Accessed January 2016.

Bureau of Labor Statistics. 2000-2016. “Local Area Unemployment Statistics Series: Various Michigan Counties Not Seasonally Adjusted.” Accessed November 2017.

Bureau of Labor Statistics. 2010. "Quarterly Census of Employment and Wages, By Industry, Annual Averages.” Accessed January 2016.

Calonico, Sebastian, Matias D. Cattaneo, and Rocio Titiunik. 2014. "Robust Nonparametric Confidence Intervals for Regression-Discontinuity Designs.” Econometrica, 82(6): 2295-2326.

Center for Healthcare Research \& Transformation. 2012. "Medicaid Eligibility in Michigan: 40 Ways."

Chetty, Raj. 2008. “Moral Hazard versus Liquidity and Optimal Unemployment Insurance.” Journal of Political Economy, 116(2): 173-234.

Cullen, Julie Berry, and Jonathan Gruber. 2000. "Does Unemployment Insurance Crowd out Spousal Labor Supply?” Journal of Labor Economics, 18(3): 546-572.

Cutler, David M., and Jonathan Gruber. 1996. "Does Public Insurance Crowd Out Private Insurance.” The Quarterly Journal of Economics, 111(2): 391-430.

Ganong, Peter, and Jeffrey B. Liebman. 2013. "The Decline, Rebound, and Further Rise in SNAP Enrollment: Disentangling Business Cycle Fluctuations and Policy Changes." National Bureau of Economic Research Working Paper 19363.

Ganong, Peter, and Pacal Noel. 2017. "Consumer spending during unemployment: Positive and normative implications." Washington Center for Equitable Growth Working Paper.

Gruber, Jonathan. 1997. "The Consumption Smoothing Benefits of Unemployment Insurance." The American Economic Review, 87(1): 192-205.

Imbens, Guido, and Karthik Kalyanaraman. 2012. "Optimal Bandwidth Choice for the Regression Discontinuity Estimator." The Review of Economic Studies, 79(3): 933-959.

Kaiser Family Foundation. n.d.. "State Health Facts: Medicaid Spending per Enrollee (Full or Partial Benefit)." Accessed May 2015. 
Kawano, Laura, and Sara LaLumia. 2014. "The Added Worker Effect Revisited: Differential Responses by Husbands and Wives."

Krueger, Alan B., Judd Cramer, and David Cho. 2014. "Are the Long-Term Unemployed on the Margins of the Labor Market?" Brookings Institution Brookings Panel on Economic Activity Final Conference Draft.

Lawson, Nicholas. 2017. "Fiscal Externalities and Optimal Unemployment Insurance." American Economic Journal: Economic Policy, 9(4).

Leung, Pauline, and Christopher O'Leary. Forthcoming. "Data and Code for: Unemployment Insurance and Means-Tested Program Interactions: Evidence from Administrative Data."

Loprest, Pamela. 2012. "How Has the TANF Caseload Changed over Time?" Urban Institute Temporary Assistance for Needy Families Program - Research Synthesis Brief Series 8.

National Bureau of Economic Research. n.d.. "NBER Internet Taxsim (Version 9)."

Rothstein, Jesse. 2011. "Unemployment Insurance and Job Search in the Great Recession.” Brookings Papers on Economic Activities, Fall: 143-196.

Rothstein, Jesse, and Robert G. Valletta. 2014. "Scraping By: Income and Program Participation After the Loss of Extended Unemployment Benefits." Federal Reserve Bank of San Francisco Working Paper 2014-06.

Ruggles, Steven, Sarah Flood, Ronald Goeken, Josiah Grover, Erin Meyer, Jose Pacas, and Matthew Sobek. 2019. "IPUMS USA: Version 9.0 [dataset].” Accessed February 2018.

Sommers, Benjamin D., and Arnold M. Epstein. 2010. "Medicaid Expansion - The Soft Underbelly of Health Care Reform?” New England Journal of Medicine, 363: 2085-2087.

U.S. Department of Labor. 2000-2017. "Comparison of State Unemployment Insurance Laws, 2000-2017."

U.S. Department of Labor. 2002-2015a. "Emergency Unemployment Compensation Trigger Notice, October 2002 - July 2015.” Accessed August 2015.

U.S. Department of Labor. 2002-2015b. "Extended Benefits Trigger Notice, October 2002 - July 2015." Accessed August 2015. 